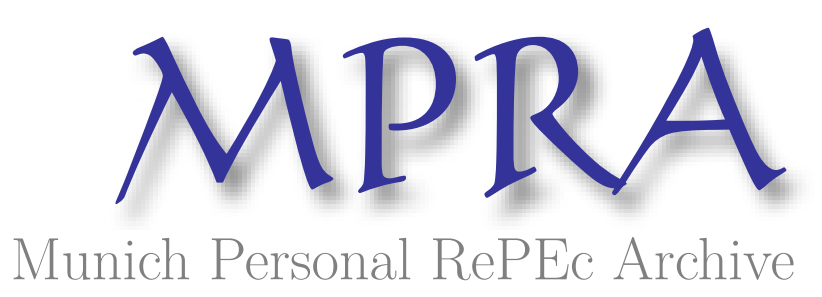

\title{
General Equilibrium Model of Arbitrage Trade and Real Exchange Rate Persistence
}

Berka, Martin

August 2005

Online at https://mpra.ub.uni-muenchen.de/234/

MPRA Paper No. 234, posted 11 Oct 2006 UTC 


\title{
General equilibrium model of arbitrage trade and real exchange rate persistence
}

\author{
Martin Berka \\ Department of Commerce, Massey University*
}

\begin{abstract}
Modelling of the physical characteristics of goods and geography can explain both the puzzling persistence and volatility in the deviations of the international relative prices and the real exchange rate (the PPP persistence puzzle). In a two-country, three-good general equilibrium model, arbitrage firms trade goods across borders using a linear transportation technology. Distance and product weights (their physical mass) determine the costs to arbitrage trade, while the differences in the endowments between countries create profitable trading opportunities. Tradability of goods is endogenous, in that only goods with a deviation from the law of one price in excess of their trade cost are traded. The adjustment of prices across borders is non-linear, with heterogeneous thresholds that depend positively on the weight of a product and distance - an empirical regularity. Aggregation of the law of one price deviations implies a smooth threshold non-linearity in the real exchange rate, justifying a reoccurring finding in the recent empirical literature. When stochastic endowments follow an $\operatorname{AR}(1)$ process calibrated to match the quarterly HP-filtered US and EU GDPs, and the aggregate trade costs consume $1.7 \%$ of the GDP, the half-life of deviation in the real exchange rate matches the persistence found in the data. A model with quadratic adjustment costs in the volume of trade is also capable of creating real exchange rate volatility, and so can explain the PPP puzzle entirely as a trade phenomenon.
\end{abstract}

Keywords: Arbitrage trade, real exchange rate, persistence, volatility

JEL Classification:

I would like to thank Michael B. Devereux, John F. Helliwell and James M. Nason for their encouragement and support. I have also benefited from discussions with Jenny Xu and Henry Siu. All errors and omissions are mine.

*Private Bag 102 904, Auckland, New Zealand, ph: +649-414-0800 ext 9474, fax: +649-441-8177, email: m.berka@massey.ac.nz 


\section{Introduction}

This paper explains persistence and volatility of real exchange rate deviations as a result of heterogeneous shipping costs in a dynamic general equilibrium framework with arbitrage trade.

The concept of purchasing power parity (PPP) maintains that national price levels should be equal when expressed in the units of a common currency (Cassel (1918)). Translated into observables, it states that the real exchange rate (a ratio of price indexes in two countries expressed in terms of a single currency) should be constant. The central puzzle in the international business cycle literature is that fluctuations in the real exchange rate are very large and very persistent. Traditionally, attempts to address this puzzle were based on the Harrod-Balassa-Samuelson objection to PPP, utilizing the distinction between traded and non-traded goods (Balassa (1961)). The real exchange rate then equals the relative price of non-traded goods to traded goods. However, these models were shown to be empirically unwarranted for developed economies ${ }^{1}$. Most notably, Engel (1999) shows that in the U.S. data, no more than $2 \%$ of the variation in the real exchange rate can be attributed to the fluctuations in the relative price of non-traded to traded goods. Many empirical studies document large, volatile and persistent deviations in the prices of traded goods across countries.

Several avenues have been explored to motivate the deviations in prices of traded goods from parity. Pricing to market with segmented markets and nominal rigidities creates volatile deviations in the real exchange rate (Betts \& Devereux (2000), Bergin \& Feenstra (2001)). A year-long price stickiness combined with a low degree of intertemporal elasticity of substitution and consumption - leisure separable preferences generates sufficient volatility but not sufficient persistence in the real exchange rate (Devereux (1997), Chari, Kehoe \& McGrattan (2002)). A distribution costs approach (e.g., Corsetti \& Dedola (2002), Burstein, Neves \& Rebello (2003)) justifies wedges between the prices of tradable goods by very large costs to product distribution (up to $60 \%$ of product price) in order to match the volatility of the real exchange rate. Differences in preferences across countries have also been used to rationalize deviations from the law of one price (e.g., Lapham \& Vigneault (2001)) but must resort to volatile and highly persistent shocks to the preference substitution parameters in order to match the observed fluctuations in the prices of traded goods. Finally, models of the costs of arbitrage trade were relatively unsuccessful in generating deviations from the law of one price (e.g., Obstfeld \& Rogoff (2000), Dumas (1992), Ohanian \& Stockman (1997), Prakash \& Taylor (1997), Sercu, Uppal \& van Hulle (1995)). This paper fits into the last strand of literature.

A recent empirical regularity is the finding that the law of one price deviations behave in a non-linear and heterogeneous way (e.g., O'Connel \& Wei (2002), Crucini, Telmer \& Zachariadis $(2001,2005))$. The source of this heterogeneity has not yet been fully understood. Using aggregate CPI as well as its four major components for cities in Europe and North America, Obstfeld and Taylor (1997) document the upward bias

\footnotetext{
${ }^{1}$ Harrod-Balassa-Samuelson proposition holds holds better for emerging and developing economies, and at lower frequencies. See, i.a., Choudhri \& Khan (2004)
} 
of AR estimations of half life of deviations when data-generating process is thresholdnonlinear. The heterogeneity of their threshold estimates is significantly related to exchange rate volatility and for some subgroups of goods to city distances. Zussman (2002) estimates TAR $(2,1,1)$ models on annual, quarterly and monthly bilateral real exchange rates for 108 countries and finds that the threshold estimates are significantly positively related to distance, import taxes, and nominal exchange rate volatility between countries. Imbs et. al. (2003) find non-linear adjustment at sectoral level and show that the heterogeneity relates to distance and nominal exchange rate volatility. Berka (2002) shows that for disaggregated law of one price deviations between US and Canada, TAR $(2, \mathrm{p}, \mathrm{d})$ threshold estimates as well as conditional convergence speeds are significantly negatively correlated to price-to-weight and price-to-volume ratios for individual products. Price differences for heavier (or more bulky) goods sustain larger deviations before becoming mean-reverting. Moreover, deviations for heavier (more bulky) goods converge more slowly once said threshold has been crossed. This suggests that shipping costs are important in explaining the heterogeneous behaviour of law of one price deviations ${ }^{2}$. In the spirit of the border effect literature (Helliwell (1998)) other candidate explanations of threshold heterogeneity may include home bias in preferences as well as some degree of domestic networking for certain types of goods, as well as distribution costs.

This paper aims to analyze the implications of such heterogeneity for real exchange rate dynamics. The two general equilibrium models presented here show how physical characteristics of goods (or heterogeneous characteristics relevant for shipment in general) can explain persistence in deviations of good prices - and the real exchange rate - from parity. In an endowment world inhabited by identical consumers, three consumption goods are traded across borders for arbitrage purposes ${ }^{3}$. Goods only differ in their weight (a physical mass), which matters for shipment. Trade is carried out by arbitrage trading firms who decide on the timing and magnitude of trade in order to maximize their profits. Arbitrage revenue depends on the size of the price difference and the volume of trade. Arbitrage costs in the first model depend on the shipping distance and the physical characteristic of the good relevant for shipment. Following a profitable arbitrage opportunity, firms engage in trade which leads to price adjustment that eliminates all profitable arbitrage opportunities. All trade takes place within the period. In the second model, arbitrage costs also include quadratic adjustment costs in the change of trade volume. Large changes in the volume of trade are more than proportionately costly due to necessary changes in legal contracts, infrastructure, etc. In such environment, firms optimally smooth the trade volume leading to more volatile price differentials.

The equilibrium of both models has three notable characteristics. First, the trad-

\footnotetext{
${ }^{2}$ For evidence that shipping costs depend on weight or volume of transported goods, see, e.g., Hummels (1999).

${ }^{3}$ The relevance of this modelling approach does not require existence of a large amount of arbitrage trade between countries. After all a threat of arbitrage should be sufficient in keeping a check on price deviations. We may also think of arbitrage trade as a limiting case of specialized production and trade of substitutable goods. Finally, arbitrage trade allows for a simple way of introducing shipping costs into the model.
} 
ability of goods is determined endogenously. In autarky, goods prices depend on endowments and household preferences. Prices can differ between the countries as long as such difference for any good does not exceed the marginal cost of trade. When it does, arbitrage firms choose an optimal amount of trade until prices adjust sufficiently to eliminate all arbitrage profit opportunities. Hence, tradability of any good is determined by the endowment shock as well as the physical characteristics the product. Second, price differences behave in a non-linear manner. They specifically exhibit threshold non-linearity where the size of the symmetric threshold - marginal cost of trade - is a function of the physical characteristics of goods and distance of the countries. Finally, the size of the law of one price deviation depends on physical characteristics of all products, as well as the size of their endowments.

Logarithm of the real exchange rate exhibits string-nonlinearity, in line with recent empirical findings (Taylor, Peel \& Sarno (2001), Kilian \& Taylor (2003)). Approximately, log real exchange rate equals a weighted average of logs price deviations. For large deviations of RER from parity, thresholds of all goods are crossed, yielding a stronger mean-reverting tendency due to larger arbitrage trade volume. When stochastic endowments follow an AR(1) process, the model can generate arbitrarily large half lives of the real exchange rate deviations. Persistence of model real exchange rate is increasing in the size of the trade friction and persistence of endowment shocks and decreasing in the volatility of the endowment shocks. Volatility of the real exchange rate depends positively on all three of the above factors and is specifically concave in shock volatility.

A careful calibration of the first model matches exactly the persistence of real exchange rate found in the data. It also generates a quantitatively close match to the persistence and co-movements of various price- and quantity- constructs. However, the model fails to create sufficient volatility in real exchange rate.

The difficulty in generating high real exchange rate volatility in the model with linear trade costs is that transportation costs are calibrated to an average $1.3 \%$ of good's value. Without any other frictions, arbitrage is triggered for relatively small shocks. The second model adds quadratic adjustment costs in the change of volume of trade. Relatively larger changes in the volume of trade are more than proportionately costly because of the needed legal and infrastructure costs, such as costs of establishing new (or changing existing) business relationships and distribution networks.

Addition of a quadratic adjustment cost to firm's decision yields a dynamic and highly non-linear model and improves results. The model retains its core feature heterogeneous trade costs - and creates a dynamic environment. Because of the costs of adjustment, trading firms chose smoother volume of trade in response to an endowment shock. Gradual (partial) volume adjustment requires price differences to exceed trade costs and leads to more persistent and more volatile deviations from law of one price and consequently real exchange rate path. Importantly, expectations of the future levels of endowment shocks enter firm's optimal decision rule. These include expectations of a threshold non-linearity (trade - no trade, modelled as an indicator function), making the second model difficult to solve.

Calibration of the second model matches both persistence and volatility of the real exchange rate while giving qualitatively meaningful results along other dimensions. It 
suggests that persistence and volatility of the purchasing power parity puzzle can be explained by careful modelling of trade costs.

The rest of the paper is structured as follows. Section 2 exposes the general equilibrium model of arbitrage trade with linear heterogeneous shipping costs and analyzes its equilibrium properties. Section 3 analyzes the properties of the arbitrage trade model that also has quadratic adjustment costs in trade volume. Section 4 constructs and analyzes stochastic properties of the real exchange rate in a variety of environments. Section 5 discusses parameter calibration. Section 6 analyzes persistence, comovement and volatility of the real exchange rate and other variables. Section 7 concludes and suggests avenues for future research.

\section{General equilibrium model of arbitrage trade}

The two-country world consists of households and arbitrage trading firms. Each country is endowed with positive amounts of three tradable goods. Goods differ in their physical characteristics, proxied here by their weight. The trade is costly because the arbitrage firm has to use resources to ship goods across borders. As shown in the transportation literature, physical characteristics of goods are an important determinant of the shipment costs (e.g., Hummels (1999)). Transportation uses one of the goods as its resource (that good is also valued for consumption). This numeraire good has a zero trade friction ${ }^{4}$. The cost of shipment is assumed to be linear in the weight of the product: shipment of $\mathrm{X}$ tons of any good between two equidistant locations will cost $\mathrm{X}$ times the shipping of one ton of a $\operatorname{good}^{5}$.

\subsection{Households}

A representative household at Home chooses its consumption path to maximize instantaneous CES utility function subject to a resource budget constraint:

$$
\begin{array}{ll} 
& \max _{C_{1 t}, C_{2 t}, C_{3 t}} \sum_{t=1}^{\infty} \beta^{t}\left\{\frac{1}{1-\theta}\left[\gamma_{1}^{\frac{1}{\theta}} C_{1 t}^{1-\frac{1}{\theta}}+\gamma_{2}^{\frac{1}{\theta}} C_{2 t}^{1-\frac{1}{\theta}}+\gamma_{3}^{\frac{1}{\theta}} C_{3 t}^{1-\frac{1}{\theta}}\right]^{1-\theta}\right\} \\
\text { s.t. } & p_{1 t} C_{1 t}+p_{2 t} C_{2 t}+C_{3 t}=p_{1 t} Y_{1 t}+p_{2 t} Y_{2 t}+Y_{3 t}+\frac{1}{2} A P_{t}
\end{array}
$$

given $A P_{t}$ and $Y_{i t}, i=\{1,2\}$, where $Y_{i t}$ is an endowment of good $i$ at time $t, \sum_{i=1}^{3} \gamma_{i}=1$, $\theta>1, p_{i t}(i=1,2)$ is the relative price of goods $i$ to good 3 and $A P_{t}$ is the amount of current-period arbitrage profits transferred to the household from a firm, assuming an equal splitting rule between households at home and abroad. The first order conditions

\footnotetext{
${ }^{4}$ The zero trade friction is an innocuous assumption. A positive friction for each good would make the computation more complicated but would not change the nature of the results.

${ }^{5}$ Insurance costs, costs of setting up distribution networks, and other costs are ignored in this specification of the transportation technology. This simplification is for the purpose of expositional clarity and mathematical simplicity.
} 
for this problem imply the usual demand functions:

$$
\begin{aligned}
C_{1 t} & =\gamma_{1} p_{1 t}^{-\theta} \frac{Y_{t}}{P_{t}^{1-\theta}} \\
C_{2 t} & =\gamma_{2} p_{2 t}^{-\theta} \frac{Y_{t}}{P_{t}^{1-\theta}} \\
C_{3 t} & =\gamma_{3} \frac{Y_{t}}{P_{t}^{1-\theta}}
\end{aligned}
$$

where $Y_{t}$ is home country's real GDP expressed in the units of good $3\left(Y_{t}=p_{1 t} Y_{1 t}+\right.$ $\left.p_{2 t} Y_{2 t}+Y_{3 t}+\frac{1}{2} A P_{t}\right)$ and $P_{t}$ is a composite price index $\left.P_{t}=\left(\gamma_{1} p_{1 t}^{1-\theta}+\gamma_{2} p_{2 t}^{1-\theta}+\gamma_{3}\right)^{\frac{1}{1-\theta}}\right)$. Preferences of households at Home and Abroad are identical, with prices abroad denoted by an asterix.

\subsection{Arbitrage trading firms}

There is a representative arbitrage trading firm in each country. It chooses the time and amount traded of each good, taking into account the transportation costs. Costs are introduced in a way of a linear transportation technology which uses good 3 as an input.

$$
\begin{aligned}
\max _{N_{1}, N_{2}, N_{3}} A \Pi_{t} & =\max _{N_{1}, N_{2}, N_{3}} \sum_{t=1}^{\infty} \beta^{t} A P_{t} \\
& =\max _{N_{1}, N_{2}, N_{3}} \sum_{t=1}^{\infty} \beta^{t}\left[\sum_{i=1}^{3}\left(p_{i t}^{*}-p_{i t}\right) N_{i t}-T\left(N_{1 t}, N_{2 t}\right)\right]
\end{aligned}
$$

where $N_{i t}$ is the amount of trade in good $i(N>0$ implies exports from Home to Abroad) and $T\left(N_{1 t}, N_{2 t}\right)$ is the cost function of the arbitrage trading firm. An arbitrage firm has to purchase $T\left(N_{1}, N_{2}\right)$ units of good 3 to trade $\left\{N_{1}, N_{2}\right\} . N_{3}$ does not enter $\mathrm{T}($.$) because the trade in good 3$ is costless ${ }^{6}$. The cost function is linear, accounting only for the shipment cost of $N_{i}$ units of a good. Model in section 3 adds a quadratic adjustment cost in the volume of trade to proxy for other costs (legal, insurance, labour, etc.). Here,

$$
T\left(N_{1 t}, N_{2 t}\right)=\left(t_{1}\left|N_{1 t}\right|+t_{2}\left|N_{2 t}\right|\right)=\left(a w_{1}\left|N_{1 t}\right|+a w_{2}\left|N_{2 t}\right|\right)
$$

where the heterogeneous trade friction $t_{i}$ is assumed to be a linear function of the weight of a good $i w_{i}$ and a positive constant homogeneous component of the shipping cost $a^{7}$. The first order conditions for the arbitrage trading firm approximately yield:

$$
\begin{aligned}
& \mathrm{I}(\mathrm{N})\left(p_{1}^{*}-p_{1}\right)=a w_{1} \quad \text { iff }\left|N_{1}\right|>0 \\
& \mathrm{I}(\mathrm{N})\left(p_{1}^{*}-p_{1}\right)<a w_{1} \quad \text { iff } N_{1}=0 \\
& \mathrm{I}(\mathrm{N})\left(p_{2}^{*}-p_{2}\right)=a w_{2} \quad \text { iff }\left|N_{2}\right|>0 \\
& \mathrm{I}(\mathrm{N})\left(p_{2}^{*}-p_{2}\right)<a w_{2} \quad \text { iff } N_{2}=0
\end{aligned}
$$

\footnotetext{
${ }^{6}$ Parameters $t_{1}$ and $t_{2}$ can be thought of as trade frictions of goods 1 and 2 relative to the trade friction of good 3 .

${ }^{7} a$ can be thought of as a per-kilogram fraction of good 3 which is used when a good is transported between Home and Abroad.
} 
where $\mathrm{I}(\mathrm{N})$ is an indicator function, such that $\mathrm{I}(\mathrm{N})=1$ when $N \geq 0, \mathrm{I}(\mathrm{N})=-1$ otherwise. Trade occurs when the marginal revenue of arbitrage (left-hand side of (6)) exceeds the marginal cost (right-hand side (6)). Trade brings about price convergence, and stops when all profit opportunities are eliminated. Hence, following trade, absolute value of price deviation equals marginal trade cost, and the FOC holds with equality. FOCs hold with inequality only in autarky. The first two pricing equations can be rewritten to show the first-order effect of good heterogeneity:

$$
\mathrm{I}(\mathrm{N}) \frac{p_{i}^{*}-p_{i}}{w_{i}} \leq a, \quad i=1,2
$$

or, more intuitively,

$$
-a \leq \overbrace{\frac{p_{i}^{*}-p_{i}}{w_{i}}}^{\text {MRA per kg }} \leq \overbrace{a}^{\text {MCA per kg }} i=1,2
$$

The left-hand side of equation (8) captures the marginal arbitrage revenue per kilogram of good $i\left(M R_{i}\right)$ and the right-hand side the marginal arbitrage cost per kilogram of good $i\left(M C_{i}\right)$. While the right-hand side is identical across goods, the left-hand side is not. Goods that are relatively heavier will need a larger deviation from the law of one price in order for MRA to exceed MCA and trigger arbitrage. First order conditions therefore imply a maximum law of one price deviation for each good proportional to its weight:

$$
\begin{aligned}
& \overbrace{\left|p_{1}^{*}-p_{1}\right|}^{\text {LOPD }} \leq t_{1} \\
& \left|p_{2}^{*}-p_{2}\right| \leq t_{2}
\end{aligned}
$$

This leads to heterogeneous filtering. Consider some shock $x$ that leads to an identical law of one price deviation for goods 1 and 2 (for example, an identical percentage increase in home endowments of both goods). The value of such shock can be divided into three subsets in terms of its effect on the price deviations. For a positive law of one price deviation, $x \in\left[0, x_{1}^{*}\right)$ leads to autarky because the law of one price deviations for goods 1 and 2 are in a no-trade region $\left(\left|L O P D_{i}\right|<t_{i} \Longleftrightarrow M R_{i}<M C_{i} \quad i=1,2\right)$. For $x \in\left[x_{1}^{*}, x_{2}^{*}\right.$ ), only the lighter good (thereafter good 1) is traded because at the time of shock price difference for good 1 exceeds $t_{1}$ but price difference for good 2 does not exceed $t_{2}:\left|L O P D_{1}\right|>t_{1} \Longleftrightarrow M R_{1}>M C_{1},\left|L O P D_{2}\right|<t_{2} \Longleftrightarrow M R_{2}<M C_{2}$. For $x \in\left[x_{2}^{*}, \infty\right)$, all goods are traded as their initial law of one price deviations are outside the no-trade region $\left(\left|L O P D_{i}\right|>t_{i} \Longleftrightarrow M R_{i}>M C_{i} \quad i=1,2\right)$. Identical endowment shocks can have differential effects on the price deviations ${ }^{8}$. Some goods will become traded while others will not. Consequently, prices will adjust in a heterogeneous fashion.

\footnotetext{
${ }^{8}$ In case $2, p_{2}$ of the heavier good will adjust due to substitution and welfare effects of a change in $p_{1}$.
} 


\subsection{Market clearing}

Three goods markets clear at home as well as abroad. The direction of trade in goods 1 and 2 depends on the size and sign of the initial deviation from a law of one price, as determined by the endowments of these goods. With only two countries, $N_{i} \equiv$ $E X P_{i}=I M P_{i}^{*}=-E X P_{i}^{*} \equiv-N_{i}^{*}$. The market clearing conditions can then be written as follows.

$$
\begin{aligned}
& C_{1}+N_{1}=Y_{1}, \quad C_{1}^{*}-N_{1}=Y_{1}^{*} \\
& C_{2}+N_{2}=Y_{2}, \quad C_{2}^{*}-N_{2}=Y_{2}^{*} \\
& C_{3}+N_{3}+\frac{1}{2} T\left(N_{1}, N_{2}\right)=Y_{3}, \quad C_{3}^{*}-N_{3}+\frac{1}{2} T\left(N_{1}, N_{2}\right)=Y_{3}^{*}
\end{aligned}
$$

\subsection{Equilibrium}

The equilibrium is a set of prices and quantities $\left\{p_{1}, p_{1}^{*}, p_{2}, p_{2}^{*}, C_{1}, C_{1}^{*}, C_{2}, C_{2}^{*}, C_{3}, C_{3}^{*}, N_{1}\right.$, $N_{2}, N_{3}$ \} such that the households maximize their utility (equations (1)-(4)), arbitrage trading firms maximize their profits (equations (9) to (10)) and markets clear (equations $(11)-(13))$.

\subsubsection{Frictionless trade}

Without transportation costs $\left(t_{i}=0 \Rightarrow T\left(N_{1}, N_{2}\right)=0\right)$, profit maximization problem faced by the arbitrage trading firm implies that law of one price holds for all goods:

$$
p_{i}^{*}=p_{i} \quad i \in\{1,2\} .
$$

The equilibrium relative prices then depend on the world endowments and the preference parameters:

$$
\frac{p_{i}}{p_{j}}=\frac{p_{i}^{*}}{p_{j}^{*}}=\left[\frac{Y_{i}^{W}}{Y_{j}^{W}} \frac{\gamma_{j}}{\gamma_{i}}\right]^{-\frac{1}{\theta}} \forall i
$$

where $Y_{i}^{W} \equiv Y_{i}+Y_{i}^{*}$. The equilibrium consumption levels are

$$
\begin{aligned}
& C_{1}=Y_{1} \frac{\left(\frac{\gamma_{1}}{\gamma_{2}}\right)^{\frac{1}{\theta}}\left(\frac{Y_{2}^{W}}{Y_{1}^{W}}\right)^{\frac{1}{\theta}}+\frac{Y_{2}}{Y_{1}}}{\left(\frac{\gamma_{1}}{\gamma_{2}}\right)^{\frac{1}{\theta}}\left(\frac{Y_{2}^{W}}{Y_{1}^{W}}\right)^{\frac{1}{\theta}}+\frac{Y_{2}^{W}}{Y_{1}^{W}}} \\
& C_{2}=Y_{1} \frac{Y_{2}^{W}}{Y_{1}^{W}} \frac{\left(\frac{\gamma_{1}}{\gamma_{2}}\right)^{\frac{1}{\theta}}\left(\frac{Y_{2}^{W}}{Y_{1}^{W}}\right)^{\frac{1}{\theta}}+\frac{Y_{2}}{Y_{1}}}{\left(\frac{\gamma_{1}}{\gamma_{2}}\right)^{\frac{1}{\theta}}\left(\frac{Y_{2}^{W}}{Y_{1}^{W}}\right)^{\frac{1}{\theta}}+\frac{Y_{2}^{W}}{Y_{1}^{W}}}
\end{aligned}
$$

similarly for $C_{1}^{*}$ and $C_{2}^{*}$ when all $Y_{i}$ in above equations are changed for $Y_{i}^{*}$. $C_{i}=$ $Y_{i}, C_{i}^{*}=Y_{i}^{*}$ iff $\frac{Y_{1}}{Y_{2}}=\frac{Y_{1}^{*}}{Y_{2}^{*}}$. The usual comparative advantage argument ensues: the country that is endowed with a relatively larger amount of good $i$ will export good $i$ and import good $j$. 


\subsubsection{Equilibrium with positive trade frictions $t_{2}>t_{1}>0$}

With positive trade frictions, three cases can arise. First, if endowments are such that the autarky deviations from law of one price are less than marginal costs of arbitrage trade (i.e., (9) and (10) hold with inequality), no goods are traded. Second, if the endowments lead to autarky prices which exceed the marginal cost of arbitrage for one good but not the other, trade occurs in the good with a relatively smaller friction $((9)$ holds with equality) while the good with a relatively larger friction is not traded ((10) holds with inequality). Finally, for endowments which lead to autarky prices such that the law of one price exceeds $\mathrm{MC}_{i} \forall i \in\{1,2\}$, both goods are traded. In summarize the equilibrium in all three cases.

Case 1: No trade in goods $1 \& 2$ When the autarky prices $\left\{p_{1 a}, p_{1 a}^{*}, p_{2 a}, p_{2 a}^{*}\right\}$ are such that (9) and (10) hold with inequalities, $N_{1}=N_{2}=0$ in equilibrium. Then

$$
\begin{array}{ll}
\gamma_{1} p_{1}^{-\theta} \frac{Y}{P^{1-\theta}}=Y_{1}, & \gamma_{1} p_{1}^{*-\theta} \frac{Y^{*}}{P^{* 1-\theta}}=Y_{1}^{*} \\
\gamma_{2} p_{2}^{-\theta} \frac{Y}{P^{1-\theta}}=Y_{2}, & \gamma_{2} p_{2}^{*-\theta} \frac{Y^{*}}{P^{* 1-\theta}}=Y_{2}^{*} \\
& \gamma_{3}\left(\frac{Y}{P^{1-\theta}}+\frac{Y^{*}}{P^{* 1-\theta}}\right)=Y_{3}+Y_{3}^{*}
\end{array}
$$

where $Y=p_{1} Y_{1}+p_{2} Y_{2}+Y_{3}, Y^{*}=p_{1}^{*} Y_{1}^{*}+p_{2} Y_{2}^{*}+Y_{3}^{*}, P=\left(\gamma_{1} p_{1}^{1-\theta}+\gamma_{2} p_{2}^{1-\theta}+\gamma_{3}\right)^{1 /(1-\theta)}$ and $P^{*}=\left(\gamma_{1} p_{1}^{* 1-\theta}+\gamma_{2} p_{2}^{* 1-\theta}+\gamma_{3}\right)^{1 /(1-\theta)}$. Walras' law implies that the system can be uniquely solved for prices $\left\{p_{1}, p_{2}, p_{1}^{*}, p_{2}^{*}\right\}$, which recursively define other equilibrium values.

Case 2: No trade in good 2 When $\left\{p_{1 a}, p_{1 a}^{*}, p_{2 a}, p_{2 a}^{*}\right\}$ are such that price difference exceeds marginal costs of arbitrage for good 1 but not for good 2 ((9) holds with equality while (10) hold with inequality), goods 2 and 3 are traded internationally while good 1 is not $\left(N_{2}=0\right.$ in equilibrium):

$$
\begin{aligned}
\gamma_{1}\left(p_{1}^{*}-I\left(N_{1}\right) t_{1}\right)^{-\theta} \frac{Y}{P^{1-\theta}}+\gamma_{1} p_{1}^{*-\theta} \frac{Y^{*}}{P^{* 1-\theta}} & =Y_{1}+Y_{1}^{*} \\
\gamma_{2} p_{2}^{*-\theta} \frac{Y}{P^{1-\theta}} & =Y_{2} \\
\gamma_{2} p_{2}^{*-\theta} \frac{Y^{*}}{P^{* 1-\theta}} & =Y_{2}^{*} \\
\gamma_{3} \frac{Y}{P^{1-\theta}}+\gamma_{3} \frac{Y^{*}}{P^{* 1-\theta}}+t_{1}\left[Y_{1}-\gamma_{1}\left(p_{1}^{*}-I\left(N_{1}\right) t_{1}\right)^{-\theta} \frac{Y}{P^{1-\theta}}\right] & =Y_{3}+Y_{3}^{*}
\end{aligned}
$$

where $\left.Y=\left(p_{1}^{*}-I\left(N_{1}\right) t_{1}\right) Y_{1}+p_{2} Y_{2}+Y_{3}\right), P=\left(\gamma_{1}\left(p_{1}^{*}-I\left(N_{1}\right) t_{1}\right)^{1-\theta}+\gamma_{2}\left(p_{2}\right)^{1-\theta}+\right.$ $\left.\gamma_{3}\right)^{1 /(1-\theta)}$ and $I($.$) is the indicator function defined in (6). Walras' law implies that this$ system uniquely determines $\left\{p_{1}^{*}, p_{2}^{*}, p_{2}\right\}$ and consequently all other equilibrium values as functions of preferences, endowments, and the trade friction $t_{1}$. 
Case 3: All goods traded Finally, when autarky price differences for both goods exceed their respective marginal costs of arbitrage, all goods are traded in equilibrium. Equilibrium prices then solve a reduced system:

$$
\begin{aligned}
\left(p_{1}^{*}-I(N) t_{1}\right)^{-\theta} \frac{Y}{P^{1-\theta}}+p_{1}^{*-\theta} \frac{Y^{*}}{P^{* 1-\theta}} & =\frac{1}{\gamma_{1}}\left(Y_{1}+Y_{1}^{*}\right) \\
\left(p_{2}^{*}-I(N) t_{2}\right)^{-\theta} \frac{Y}{P^{1-\theta}}+p_{2}^{*-\theta} \frac{Y^{*}}{P^{* 1-\theta}} & =\frac{1}{\gamma_{2}}\left(Y_{2}+Y_{2}^{*}\right) \\
\gamma_{3} \frac{Y}{P^{1-\theta}}+\gamma_{3} \frac{Y^{*}}{P^{* 1-\theta}}+t_{1}\left[Y_{1}-\gamma_{1}\left(p_{1}^{*}-I\left(N_{1}\right) t_{1}\right)^{-\theta} \frac{Y}{P^{1-\theta}}\right] & =Y_{3}+Y_{3}^{*}
\end{aligned}
$$

where $\left.Y=\left(p_{1}^{*}-I\left(N_{1}\right) t_{1}\right) Y_{1}+\left(p_{2}^{*}-I\left(N_{2}\right) t_{2}\right) Y_{2}+Y_{3}\right)$ and $P=\left(\gamma_{1}\left(p_{1}^{*}-I\left(N_{1}\right) t_{1}\right)^{1-\theta}+\right.$ $\left.\gamma_{2}\left(p_{2}-I\left(N_{2}\right) t_{2}\right)^{1-\theta}+\gamma_{3}\right)^{1 /(1-\theta)}$. Walras' law reduces the above system into two equations that solve uniquely for $\left\{p_{1}^{*}, p_{2}^{*}\right\}$ and implicitly all other variables as functions of endowments, preferences, and the trade frictions $t_{1}, t_{2}$.

\subsubsection{Properties of the equilibrium}

Trade frictions $t_{1}$ and $t_{2}$ affect equilibrium prices and allocations in all three cases: directly in cases 2 and 3 and indirectly in cases 1 and 2 by defining endowments for which the autarky solutions apply. An interesting general equilibrium effect emerges in case 2 when prices of non-traded good at home and abroad are affected by the price convergence in traded good. Consumers in exporting country substitute away from the traded good 1 (price of which rises due to shrinking domestic supply) into non-traded good 2 and consumers in the importing country move away from non-traded into traded good. Consequently, law of one price deviation for the non-traded good 2 is smaller when good 1 is traded than it would have been if good 1 was not traded. This spillover effect can be seen in figure 1 below in a smaller slope of LOPD for good 2 in case 2 than in case 1 (note good 2 is not traded in both cases).

Figure 1 plots the equilibrium law of one price deviations against the percentage change in level of relative endowment. Keeping the endowments Abroad fixed, Home endowments of goods 1 and 2 vary by the same amount, leading to changes in $p_{1}, p_{2}$ at home. This is the simplest way to perturb the model to illustrate three aforementioned cases. In case 1 , price differences are smaller than marginal costs of trade. In case 2 , trade occurs for good 1 but good 2 remains non-traded. If good 1 is exported from Home, $p_{1}$ rises and $p_{1}^{*}$ declines until $p_{1}^{*}-p_{1}=t_{1}$. Therefore, $\mathrm{LOPD}_{1}$ graph exhibits a threshold in case 2 . The substitution away from good 1 in the exporting country (Home) and towards good 1 in the importing country (Abroad) increases $p_{2}$ and lowers $p_{2}^{*}$, leading to price adjustment in non-traded good. Demand for non-traded good rises at Home and drops Abroad, leading to a lower $\mathrm{LOPD}_{2}$ than if good 1 was not traded. Consequently, slope of the $\mathrm{LOPD}_{2}$ line is smaller in case 2 than in case 1 . The prediction is that trade in one sector lowers law of one price deviations in all other non-traded sectors that have a positive degree of substitutability ${ }^{9}$. Finally, when the endowment differences induce trade in the second goods, equilibrium $\mathrm{LOPD}_{2}$ reaches a threshold. Figure 9 plots the volume of trade.

\footnotetext{
${ }^{9}$ For example, trade in shaving machines would reduce law of one price deviation in barber services.
} 
Figure 1: Model solution: thresholds of price deviations in linear model

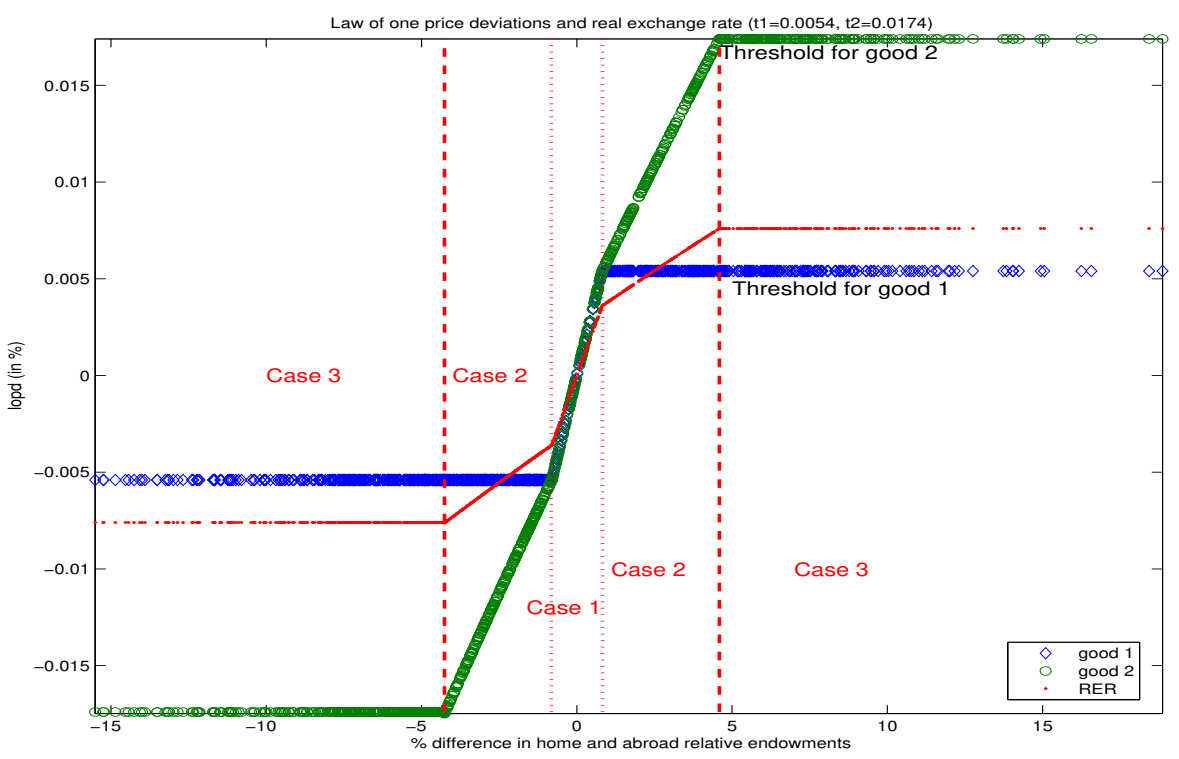

Stochastic properties of the model can be illustrated with a Monte Carlo simulation. Starting from autarkic equilibrium with identical endowments of all 3 goods in both countries, let a country-specific shock $\epsilon \sim \mathrm{N}\left(0, \sigma^{2}\right)$ change endowments of goods 1 and 2 at Home by the same amount, without any change Abroad: $Y_{1}=Y_{2}=Y+\epsilon, Y_{1}^{*}=$ $Y_{2}^{*}=Y_{3}^{*}=Y_{3} \equiv \bar{Y}$. Depending on the size of the shock, one of cases 1, 2 or 3 ensues. Figure 10 shows that price deviations of the heavier good are larger and more volatile and, as expected, that LOPD volatility is concave in $\sigma$ as larger shocks are more likely to get arbitraged away. Figures 12 - 14 illustrate robustness of this behaviour of means, volatility and thresholds of price deviations across a range of values for $t$. Because shipping costs are linear in $t$, properties of the model remain qualitatively unchanged for any $t_{2} / t_{1}$.

\section{Arbitrage trade model with adjustment costs to trade}

The second model has an identical endowment and preference setting. However, trade costs additionally include quadratic adjustment costs in the change of trade volume. Changes in the trade volume require hiring of labour resources, adjustment in the distribution system and possibly investment in new (or a changes of the existing) trade infrastructure. Adjustment to endowment shocks also requires time. Quadratic adjustment costs get at such idea of gradual response in a smoother way than does assumption of a pre-determined volume of shipment (i.a., Ravn \& Mazzenga (2002)). Consequently, large swings in trade volume are more-than-proportionately costly. The 
arbitrage firms' problem is now:

$$
\begin{aligned}
\max _{N_{1 t}, N_{2 t}} A \Pi_{t} & =\max _{N_{1 t}, N_{2 t}} \sum_{j=t}^{\infty} \beta^{(j-1)} A P_{j} \\
& =\max _{N_{1 t}, N_{2 t}} \sum_{j=t}^{\infty} \beta^{(j-1)}\left[\sum_{i=1}^{2}\left(p_{i j}^{*}-p_{i j}\right) N_{i j}-T\left(N_{1 j}, N_{2 j}\right)\right] \\
\text { s.t. } T\left(N_{1 t}, N_{2 t}\right) & =t_{1}\left|N_{1 t}\right|+t_{2}\left|N_{2 t}\right|+c_{1} \Delta N_{1 t}^{2}+c_{2} \Delta N_{2 t}^{2}
\end{aligned}
$$

where $N_{i t}$ is the amount of trade in good $i$ at time $t(N>0$ implies exports from Home to Abroad), $T\left(N_{1 t}, N_{2 t}\right)$ the cost function of the arbitrage trading firm and $p_{i t}$ the price of good $i$ relative to good 3. The firm has to purchase $T\left(N_{1 t}, N_{2 t}\right)$ units of good 3 to trade $\left\{N_{1 t}, N_{2 t}\right\}$. Because the trade in good 3 is assumed to be costless, $N_{3 t}$ does not enter $\mathrm{T}($.$) and its trade volume is determined according to the market$ clearing conditions and the preferences of households. Total cost consists of a shipping cost and adjustment cost ${ }^{10}$. Shipping cost is identical to that in the first model: $t_{i}=$ $a w_{i}, i=1,2$ where $w_{i}$ is the weight of good $i$ and $a$ is a constant. Adjustment cost is quadratic in the change of volume of trade from the previous period to the current period. Parameters $c_{1}$ and $c_{2}$ are not related to the physical characteristics of goods.

The difficulty of summarizing the behaviour of the firm with its first order conditions lies in the non-differentiability of the absolute value function at 0 . I use a smooth approximation $G($.$) to the absolute value function to allow a continuous mapping be-$ tween the first order conditions and the objective function. Let $g(.) \equiv \mathrm{d} G($.$) denote the$ first order derivative of the "smooth" absolute value function (hence, $g($.$) is a smooth$ approximation to a step function - see the Appendix A for details). The first order optimality conditions yield:

$$
\begin{aligned}
0 & =\left\{\left(p_{i, t}^{*}-p_{i, t}\right)-\frac{\partial T\left({ }_{\cdot t}\right)}{\partial N_{i, t}}-\beta \mathrm{E}_{t} \frac{\partial T\left({ }_{\cdot t+1}\right)}{\partial N_{i, t}}\right\} \\
0 & =p_{i, t}^{*}-p_{i, t}-\left[t_{i} \mathrm{I}\left(N_{i, t}\right)+2 c_{i}\left(N_{i, t}-N_{i, t-1}\right)\right]-\beta \mathrm{E}_{t}\left[-2 c_{i}\left(N_{i, t+1}-N_{i, t}\right)\right]
\end{aligned}
$$

Rearranging, we get

$$
\begin{aligned}
\frac{1}{2 c_{i}}\left[p_{i, t}^{*}-p_{i, t}-t_{i} \mathrm{I}\left(N_{i, t}\right)\right] & =-\beta \mathrm{E}_{t} N_{i, t+1}+(1+\beta) N_{i, t}-N_{i, t-1} \\
& =\left(-\beta \mathrm{B}^{-2}+(1+\beta) \mathrm{B}^{-1}-1\right) \mathrm{E}_{t} N_{i, t-1} \\
& =\left[-\beta+(1+\beta) \mathrm{B}-\mathrm{B}^{2}\right] \mathrm{E}_{t} N_{i, t+1} \forall i
\end{aligned}
$$

where B is a backshift operator and $\mathrm{I}\left(N_{i, t}\right) \equiv g($.$) is an approximation to the indicator$ function, such that $\mathrm{I}\left(N_{i, t}\right)=1$ when $N_{i, t}>0, \mathrm{I}\left(N_{i, t}\right)=-1$ when $N_{i, t}<0$ and $\mathrm{I}\left(N_{i, t}\right)=0$ when $N_{i, t}=0$. The quadratic form on the right hand side of the last equality has one stationary and one non-stationary root and can be re-written as $-(\mathrm{B}-1)(\mathrm{B}-\beta)$. The first order conditions for the firm can then be written as

$$
-\frac{1}{2 c_{i}}\left[p_{i, t}^{*}-p_{i, t}-t_{i} \mathrm{I}\left(N_{i, t}\right)\right]=\left(1-\mathrm{B}^{-1}\right)\left(1-\beta \mathrm{B}^{-1}\right) \mathrm{E}_{t} N_{i, t-1} \forall i
$$

\footnotetext{
${ }^{10}$ This is an innocuous assumption, one could calculate a more complicated version of the model with a positive trade friction for trade in each of the three goods. The parameters $t_{1}$ and $t_{2}$ can be thought of as trade frictions of goods 1 and 2 relative to the trade friction of good 3 .
} 
Expanding the stable eigenvalue forward and the unstable one backward, the first order condition for the arbitrage trading firm can be re-written in the forward-looking form:

$$
N_{i, t}=N_{i, t-1}+\frac{1}{2 c_{i}} \mathrm{E}_{t} \sum_{j=0}^{\infty} \beta^{j}\left(p_{i, t+j}^{*}-p_{i, t+j}-t_{i} \mathrm{I}\left(N_{i, t+j}\right)\right) \forall i
$$

Optimal amount of trade in good $i$ in period $t$ depends positively on the volume of trade in the past period and on the expected future path of deviations of prices from parity in excess of the trade friction. Firms care about the future path of price differentials because of they want to smooth their trade patterns over time. Expected deviation from parity in excess of trade friction in period $t+j$ increases trade in all future periods from $t$ onwards. Expected future direction of trade $\mathrm{E}_{t} \mathrm{I}\left(N_{i, t+j}\right)$ also enters firm's decision rule. Expectation of a change in the direction of trade lowers trade volume today. So, if the firm expects a future price process in which periods with expected export regime are followed by periods with expected import regime ${ }^{11}$, it optimally lowers the trade volume relative to a scenario in which the firm expects only one regime to prevail.

\subsection{Equilibrium}

The equilibrium is a set of prices and quantities $\left\{p_{1, t}, p_{1, t}^{*}, p_{2, t}, p_{2, t}^{*}, C_{1, t}, C_{1, t}^{*}, C_{2, t}, C_{2, t}^{*}, C_{3, t}\right.$, $\left.C_{3, t}^{*}, N_{1, t}, N_{2, t}, N_{3, t}\right\}_{t=0}^{\infty}$ such that the representative household maximizes its utility (equations (1)-(4)), arbitrage trading firms maximize their profits (equation (18) for both goods) and all markets clear (equations (11) - (13)). It can be simplified into a 4 -by-4 system in $\left\{p_{1, t}, p_{2, t}, p_{1, t}^{*}, p_{2, t}^{*}\right\}$ :

$$
\begin{gathered}
\Delta Y_{1, t}-\gamma_{1}\left[p_{1, t}^{-\theta} \frac{Y_{t}}{P_{t}^{1-\theta}}-p_{1, t-1}^{-\theta} \frac{Y_{t-1}}{P_{t-1}^{1-\theta}}\right]= \\
=\frac{1}{2 c_{1}} \mathrm{E}_{t} \sum_{j=0}^{\infty} \beta^{j}\left[p_{1, t+j}^{*}-p_{1, t+j}-t_{1} \mathrm{I}\left(N_{1, t+j}\right)\right] \\
\Delta Y_{2, t}-\gamma_{2}\left[p_{2, t}^{-\theta} \frac{Y_{t}}{P_{t}^{1-\theta}}-p_{2, t-1}^{-\theta} \frac{Y_{t-1}}{P_{t-1}^{1-\theta}}\right]= \\
=\frac{1}{2 c_{2}} \mathrm{E}_{t} \sum_{j=0}^{\infty} \beta^{j}\left[p_{2, t+j}^{*}-p_{2, t+j}-t_{2} \mathrm{I}\left(N_{2, t+j}\right)\right] \\
\gamma_{1} p_{1, t}^{-\theta} \frac{Y_{t}}{P_{t}^{1-\theta}}+\gamma_{1} p_{1, t}^{*-\theta} \frac{Y_{t}^{*}}{P_{t}^{* 1-\theta}}=Y_{1, t}+Y_{1, t}^{*} \\
\gamma_{2} p_{2, t}^{-\theta} \frac{Y_{t}}{P_{t}^{1-\theta}}+\gamma_{2} p_{2, t}^{*-\theta} \frac{Y_{t}^{*}}{P_{t}^{* 1-\theta}}=Y_{2, t}+Y_{2, t}^{*}
\end{gathered}
$$

where $Y_{t}=p_{1, t} Y_{1, t}+p_{2, t} Y_{2, t}+Y_{3, t}+\frac{1}{2} A P_{t}, P_{t}$ is a composite price index $\left(P_{t}=\right.$ $\left.\left(\gamma_{1} p_{1, t}^{1-\theta}+\gamma_{2} p_{2, t}^{1-\theta}+\gamma_{3}\right)^{\frac{1}{1-\theta}}\right), \mathrm{I}(N)$ is a smooth approximation to the indicator function and $A P_{t}$ are the contemporaneous arbitrage profits. Equations (19) and (20) are

\footnotetext{
${ }^{11}$ A process in which $p_{i, t+j+l}^{*}>p_{i, t+j+l}+t_{i} \Rightarrow \mathrm{I}\left(N_{i, t+j}\right)=1$ is followed by $p_{i, t+j+k}^{*}+t_{i}<p_{i, t+j+k} \Rightarrow$ $\mathrm{I}\left(N_{i, t+j+k}\right)=-1$ for $k>l$.
} 
the two intertemporal equilibrium conditions. Equations (21) and (22) are the two intratemporal equilibrium conditions.

\subsubsection{Intuition}

The intuition about new aspects adjustment costs bring to model's equilibrium can be built using a simpler one-period version. First, firm chooses a finite trade volume. Without adjustment costs, firm's optimal trade volume is infinite in partial equilibrium. Second, price deviations can exceed shipping costs in equilibrium. By the same token, trade may occur when price difference does not exceed the shipping $\operatorname{costs}^{12}$.

Consider a one-period version of the model, with only one good with a positive trade friction $t$. Firm's first order condition implies: $p^{*}-p-\mathrm{I}(N) t=2 c\left(N-N_{-1}\right)$ where $N_{-1}$ is the last period's trade volume. With $c>0$ and $\left|p^{*}-p\right|>t$, firm chooses a finite volume of trade that depends positively on the law of one price deviation $\left(p^{*}-p\right)$ and last period's trade volume $N_{-1}$, and negatively on the cost parameters $t$ and $c$. Note that the trade volume is indeterminate when $c=0$. Hence, trade can occur when $\left|p^{*}-p\right|<t$ because trading firm has to strike balance between loss-making trade and costs of trade deceleration (when $N_{-1} \neq 0$ ). Profits are necessarily negative. When

Figure 2: Volume and prices become detached due to adjustment costs $\left(N_{-1}=0\right)$
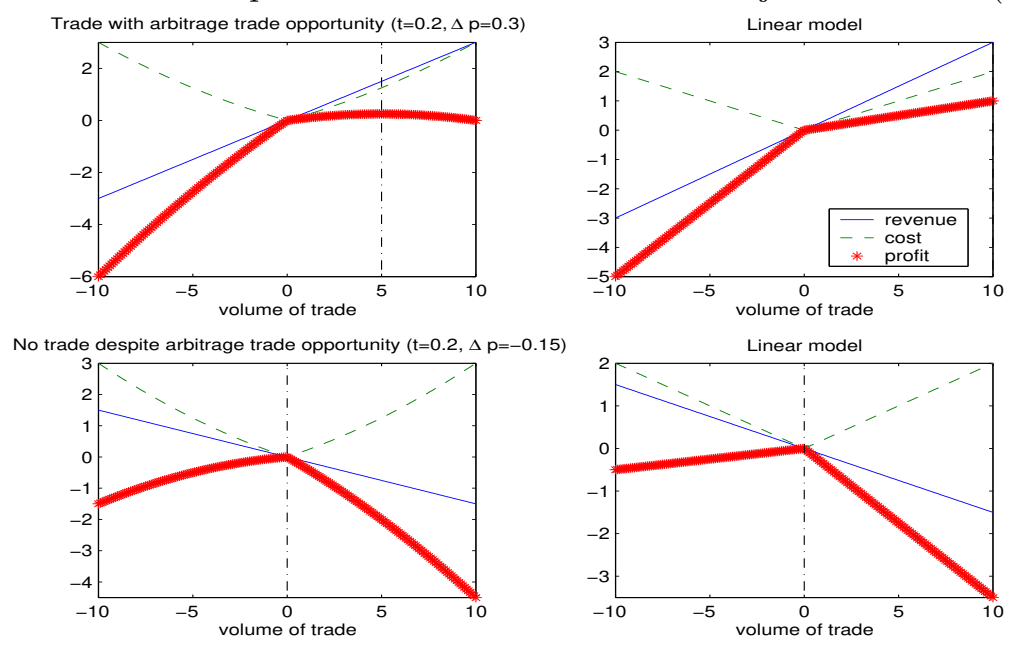

$N_{-1}=0$, trade occurs if and only if $\left|p^{*}-p\right|>t$, as it did in linear shipping cost model. In the upper half of figure (2) price abroad is $30 \%$ higher than at home. In the lower half, $p^{*}$ is $15 \%$ below $p$. Because the profit function is parabolic (with a kink) in the presence of adjustment costs, trade occurs in finite amounts. The extra cost implies lower volume of trade (upper segment of figure (2)). When $c>0$ and $N_{-1}=0$,

$$
\frac{\partial N_{i}}{\partial Y_{i}}=\frac{\pi}{2 c \theta}\left[\frac{Y_{i}^{-\frac{1}{\theta}-1}}{Y_{3}^{-\frac{1}{\theta}}}-\theta t\right]<1
$$

\footnotetext{
${ }^{12}$ Quadratic adjustment cost model nests the linear shipping cost model. Values of $c_{1}$ and $c_{2}$ in (19) and (20) determine linkage between today's and yesterday's trade $N_{i, t}$ and $N_{i, t-1}$. When $c=0,(19)$ and (20) are identical to (6) and (7).
} 
where $\pi \equiv \operatorname{prob}\left(\left|p^{*}-p\right|>t\right)$. The volume of trade will be smaller than the increase in endowment (see Appendix B for proof).

Because trade is the only source of price adjustment, a smaller trade volume requires smaller price adjustment. Consumption closer to autarky requires equilibrium prices to be closer to the autarky prices. Hence, adjustment costs can sustain equilibrium law of one price deviations in excess of threshold $t$. While the no-trade region in the quadratic adjustment cost model is identical to that in a model with linear shipment costs, law of one price deviation can exceed the shipping threshold in equilibrium. It can be shown that, in the one-period model, for any $N_{-1}$,

$$
\frac{\partial p_{i}}{\partial Y_{i}}=\mathrm{D}\left[-2 c-t \frac{\partial \mathrm{I}(N)}{\partial Y_{i}}\left(1+\frac{1}{A}\right)\right]
$$

where $\mathrm{D}>0$ and $A<-1$. An increase in the home endowment will decrease home price (increase $p^{*}-p$ ) when $c>0$. Moreover, the deviation from the law of one price is increasing in $c$ because a larger adjustment cost leads to a smaller adjustment in volume.

Figures (19)-(22) show the initial responses of deviations from the law of one price for a range of $\mathrm{d} Y_{i, 1}(i=1,2)$, as well as for a range of cost adjustment parameters $c$. As in the linear shipping cost model, three cases exist for any level of $c$ : case 1 in which none of the goods are traded, case 2 in which only the lighter good is traded and case 3 with all goods traded. As before, price of a non-traded good 2 is affected by the fact that good 1 is traded: as home price of good 1 rises, home consumers substitute to good 2. This expenditure switching effect increases home demand for the non-traded good 2, rising its price above what it would have been otherwise. Consequently, law of one price deviation for good 2 is smaller than it would have been if good 1 was not traded. Trade volume depends negatively on frictions $c$ and $t$. Cumulative trade volume expressed as a percentage of endowment change is non-monotonic. Finally, adjustment costs force firms to spread trade in more steps of smaller magnitude: time length of adjustment depends positively on $c$ and $\mathrm{d} Y_{i}$.

The intuition changes slightly when $N_{-1} \neq 0 . N=N_{-1}+\frac{1}{2 c}\left(p^{*}-p-\mathrm{I}(N) t\right)$ and so as long as the good remains traded (I $(N)$ does not change), relationship between $N$ and price deviation stays qualitatively unchanged. But the range of autarkic values of LOPD decreases in $N_{-1}$ (figure 3). When $N_{-1}>0$, costly trade deceleration can imply positive trade volume even though $p^{*}-p<t$ (the reverse can also hold). Optimality does not guarantee positive profits when $c>0$ (see figure 23). Large values of $\left|N_{-1}\right|$ require larger $\left|p^{*}-p\right|$ for profitable arbitrage trade.

\subsection{Solution method}

Due to a high degree of non-linearity, I solve the model numerically using aforementioned approximation to the step function $I\left(N_{i, t}\right)=I\left(\left\{p_{1, t+i}, p_{1, t+i}^{*}, p_{2, t+i}, p_{2, t+i}^{*}\right\}_{i=0}^{\infty}\right)$. This yields a a highly non-linear yet differentiable first order system.

First, one needs to limit the time span for adjustment. I assume existence of a steady state equilibrium to which countries converge following a shock and then decide 
Figure 3: Trade in partial equilibrium in QAC model for various LOPDs and $N_{-1} \cdot \mathrm{c}=0.01, \mathrm{t}=0.2$

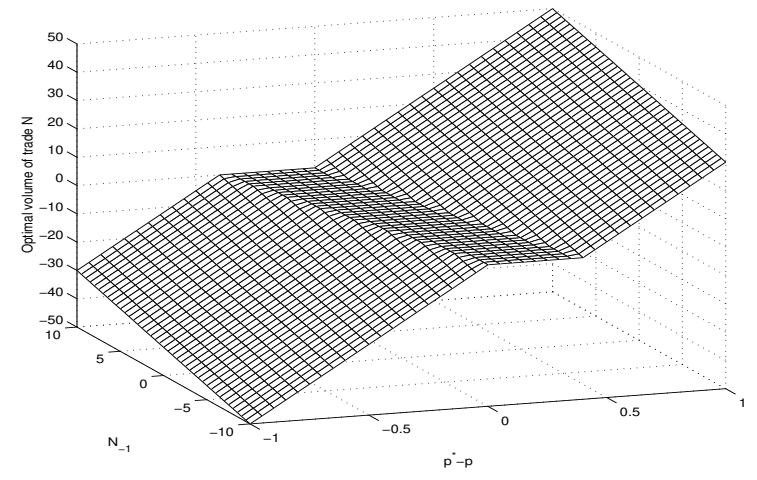

on $T$ time periods available for adjustment to a steady state. Conditional on $T$, the model can in principle be solved recursively. However, efforts to apply recursive solution methods have failed to find the equilibrium paths of the variables, primarily due to the non-linearity in the indicator function. Consequently, a method of relaxation (see Boucekkine (1995)) is applied in which a finite-period approximation $\widehat{f(.)} t_{t=1: T}=0$ to the system $f(.)_{t=1: \infty}=0$ is solved by stacking all equations for all time periods into one large system $F(.) \equiv\left[\widehat{f(.)_{t=1}} \ldots \widehat{f(.)_{t=T}}\right] \prime=0$ which is then solved numerically. The four unknown price variables in the equilibrium system $f($.$) above imply that the size$ of the Jacobian is $4 T \times 4 T$.

Second, in order to compute the Jacobian of the stacked system $F($.$) in one step, a$ smooth $I\left(N_{i, t}\right)$ function is necessary. Some creative work leads to

$$
I\left(N_{i, t}\right) \equiv \mathrm{d} G=\frac{2}{\pi} \arctan \left(\lambda N_{i, t}\right)
$$

where $\lambda$ is a choice parameter which governs the approximation error. An inverse of a trigonometric function $\tan (x), \arctan (x)$ has a range of $[-\pi / 2, \pi / 2]$ for $x \in \mathbf{R}$ and is monotonically increasing, continuously differentiable, and has a convenient property that $\arctan (x)<0$ when $x<0, \arctan (x)>0$ when $x>0$ and $\arctan (0)=0$. Because of the bounded range, and because $\arctan (\lambda x)_{x=0}=0 \forall \lambda$, $\arctan (\lambda x)$ can reach the bounds arbitrarily fast. Premultiplying the function by $2 / \pi$ changes its range to [$1,1]$, creating a "continuous step function". High $\lambda$ lowers the approximation error, as illustrated in Figure (18). A choice of $\lambda=10^{40}$ makes the approximation error indistinguishable from zero for any feasible stopping criterion of the numerical solver.

Third, to facilitate the numerical solver in finding an equilibrium, (19) and (20) are replaced with their simpler forms (25) and (26) which do not include an infinite forward-looking sum. An error in $p_{i t}$ by the numerical solver now only affects the $4(t-1): 4(t+1)$ partition of the Jacobian $\left(=12^{2}=144\right.$ values $)$, whereas before it would have influenced all $(4 T)^{2}(14400$ when $T=30)$ values of the Jacobian, preventing convergence for relatively small error levels.

$$
\frac{1}{2 c_{1}}\left(p_{1, t}^{*}-p_{1, t}-t_{1} I\left(N_{1, t}\right)\right)=(1+\beta) Y_{1, t}-\beta Y_{1, t+1}-Y_{1, t-1}
$$




$$
\begin{aligned}
& -(1+\beta) \gamma_{1} p_{1, t}^{-\theta} \frac{Y_{t}}{P_{t}^{1-\theta}}+\beta \gamma_{1} p_{1, t+1}^{-\theta} \frac{Y_{t+1}}{P_{t+1}^{1-\theta}} \\
& +\gamma_{1} p_{1, t-1}^{-\theta} \frac{Y_{t-1}}{P_{t-1}^{1-\theta}} \\
\frac{1}{2 c_{2}}\left(p_{2, t}^{*}-p_{2, t}-t_{2} I\left(N_{2, t}\right)\right)= & (1+\beta) Y_{2, t}-\beta Y_{2, t+1}-Y_{2, t-1} \\
& -(1+\beta) \gamma_{2} p_{2, t}^{-\theta} \frac{Y_{t}}{P_{t}^{1-\theta}}+\gamma_{2} \beta p_{2, t+1}^{-\theta} \frac{Y_{t+1}}{P_{t+1}^{1-\theta}} \\
& +\gamma_{2} p_{2, t-1}^{-\theta} \frac{Y_{t-1}}{P_{t-1}^{1-\theta}}
\end{aligned}
$$

A system $\widehat{f(.)})_{t=i}$, part of the large stacked system $F($.$) , consists of equations (25),$ (26), (21) and (22). Period $T+1$ values which are found in the inter-temporal Euler equations of $\widehat{f(.)_{T}}$ are set to steady-state equilibrium values associated with a full adjustment to the shock.

Finally, a two-step method is used in the calculation to ensure that the layers of approximation do not lead to a wrong solution. First, a system $F($.$) above is solved,$ and time paths of all variables are computed. Because this is merely an approximation to the true system (for smaller levels of $\lambda, I\left(N_{i, t}\right)$ can be distinguished from $1,-1$, or 0 ), a second step involves replacing the $I\left(N_{i, t}\right)$ ) with $1,-1$, or 0 using the first step estimates, and solving the system again.

\section{Real exchange rate}

This section explains the behaviour of the real exchange rate in the model using a numerical solution for a range of paramater values. A more realistic calibration exercise is conducted in Section 5 with the aim to compare the match of the model with the data. Logarithm of the real exchange rate from the model is constructed as a weighted average of the three law of one price deviations ${ }^{13}: \log (R E R)=\gamma_{1} \log \left(L O P D_{1}\right)+$ $\gamma_{2} \log \left(L O P D_{2}\right)+\gamma_{3} \log \left(L O P D_{3}\right)$. To study model's implications for persistence, I introduce an $\mathrm{AR}(1)$ endowment process at Home: $Y_{i, t}=\alpha Y_{i, t-1}+(1-\alpha) \bar{Y}+u_{t} i=1,2$ where $u_{t} \sim \mathrm{N}\left(0, \sigma^{2}\right)$.

\subsection{Real exchange rate in a linear shipping cost model}

Persistence of real exchange rate depends positively on the shipping cost, as these determine the size of a no-arbitrage threshold. Moreover, RER persistence is increasing in the ratio of $t_{2} / t_{1}$ (table 3 ). This isolates the additional effect heterogeneity of shipping costs has on the RER persistence. Persistence of the real exchange rate also depends negatively on the volatility of the endowment shocks because small (and persistent) shocks will need more time to cross a threshold.

\footnotetext{
${ }^{13}$ Each country $j$ 's CPI is a geometric average of goods and services with weights corresponding to the consumption shares. Hence, $\log \left(C P I_{t}^{j}\right)=\gamma_{1}^{j} p_{1, t}^{j}+\gamma_{2}^{j} p_{2, t}^{j}+\gamma_{3, t}^{j}$. This yields model's $\log (R E R)$ when consumption shares are same in both countries.
} 
A sufficiently small but persistent endowment shock can generate an infinite half-life of convergence because the difference is never traded away. Conditional on the trade friction, persistence of the real exchange rate is positively related to the persistence of the endowment shock process $\alpha$ (see Figure 4 and Table 1). For $\alpha<0.9$, half lives of convergence for the real exchange rate do not exceed 7 time periods. Half life increases sharply in $\alpha$ for values near 1 , to about 12 when $\alpha=0.95,30$ for $\alpha=0.975$ up to 525 time periods when the endowments follow a unit root $(\alpha=1)$. Shock variance affects half life negatively because it increases the likelihood of triggering arbitrage (and price convergence). For $\sigma=6.8 \%$ of GDP, the maximum half does not exceed 19 periods.

Figure 4: RER persistence and volatility and the shock process in linear model
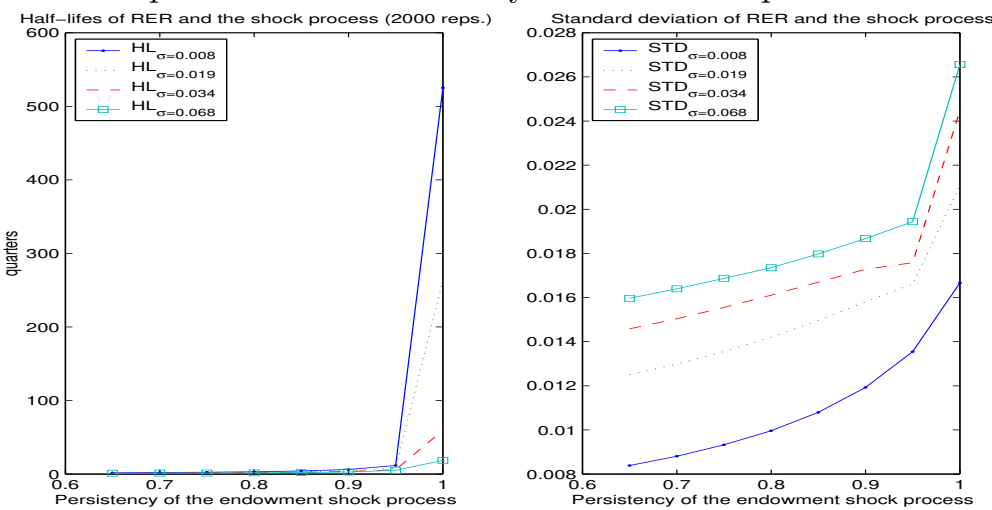

Table 1: RER half lives (in quarters) and the shock process

\begin{tabular}{ccccccccc}
\hline & $\alpha=0.65$ & $\alpha=0.7$ & $\alpha=0.75$ & $\alpha=0.8$ & $\alpha=0.85$ & $\alpha=0.9$ & $\alpha=0.95$ & $\alpha=1$ \\
\hline$\sigma=0.008$ & 1.66 & 1.99 & 2.44 & 3.11 & 4.16 & 6.13 & 11.52 & 525.12 \\
$\sigma=0.019$ & 1.42 & 1.67 & 2.00 & 2.48 & 3.18 & 4.55 & 7.93 & 263.46 \\
$\sigma=0.034$ & 1.21 & 1.41 & 1.65 & 1.98 & 2.50 & 3.50 & 5.86 & 59.39 \\
$\sigma=0.068$ & 1.02 & 1.16 & 1.34 & 1.59 & 2.03 & 2.82 & 4.99 & 18.56 \\
\hline
\end{tabular}

Each result is based on 2000 Monte Carlo simulations of the linear shipping cost model $\left(c_{i}=0 i=1,2\right)$ when $t_{1}=0.02$ and $t_{2}=0.04$. $\alpha$ is the $\operatorname{AR}(1)$ coefficient of the shock process, $\sigma$ is the standard deviation as a proportion of the mean GDP.

Volatility of the real exchange rate increases both in shock persistence $\alpha$ and shock volatility $\sigma$ (see figure 4 and table 2). Endowment shocks increase LOPD volatility as long as at least one good is not traded. Additional shock volatility that brings LOPDs in excess of $t$ in autarky is neutral because of instantaneous arbitrage. More persistent shocks lead to longer-lived deviations from the law of one price, increasing their volatility. This effect is particularly visible when $\sigma$ is small so that most shocks leave LOPD below the arbitrage thresholds (std(RER) exceeds $\sigma$, see table 2). Conversely, high $\sigma$ s only have a marginal effect on std(RER).

Size of the shipping cost is a major determinant of the persistence of the real exchange rate. For a given $\alpha$, a larger shipping friction $t$ requires a larger endowment shock in order for arbitrage trade to occur. Additionally, the fact that shipping costs are heterogeneous increases persistence as well as volatility of RER. This new effect 
Figure 5: Properties of the real exchange rate and the trade friction in linear model
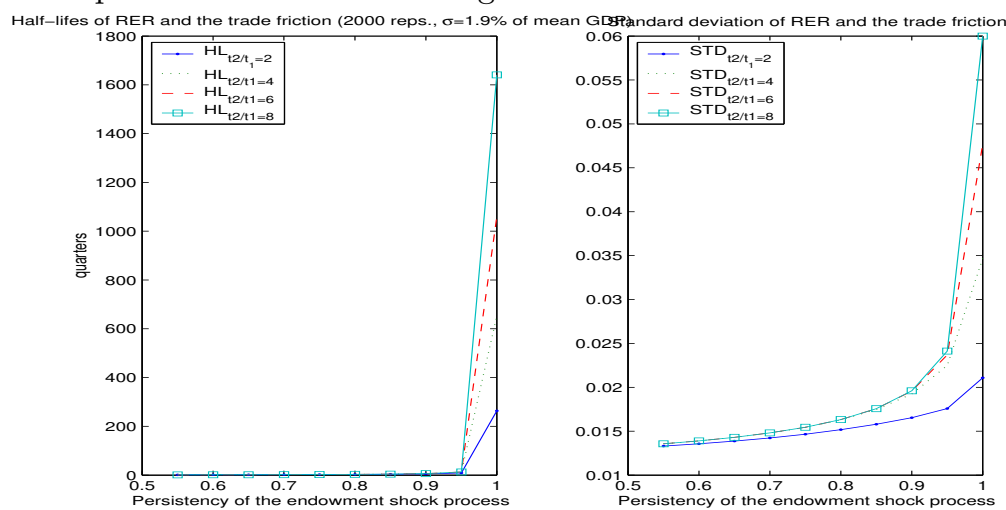

Table 2: Standard deviation of the RER and the shock process

\begin{tabular}{ccccccccc}
\hline & $\alpha=0.65$ & $\alpha=0.7$ & $\alpha=0.75$ & $\alpha=0.8$ & $\alpha=0.85$ & $\alpha=0.9$ & $\alpha=0.95$ & $\alpha=1$ \\
\hline$\sigma=0.008$ & 0.008 & 0.009 & 0.009 & 0.010 & 0.011 & 0.012 & 0.014 & 0.017 \\
$\sigma=0.019$ & 0.013 & 0.013 & 0.014 & 0.014 & 0.015 & 0.016 & 0.017 & 0.021 \\
$\sigma=0.034$ & 0.015 & 0.015 & 0.016 & 0.016 & 0.017 & 0.017 & 0.018 & 0.024 \\
$\sigma=0.068$ & 0.016 & 0.016 & 0.017 & 0.017 & 0.018 & 0.019 & 0.019 & 0.027
\end{tabular}

Each result is based on 2000 Monte Carlo simulations of the linear shipping cost model $\left(c_{i}=0 i=1,2\right)$ when $t_{1}=0.02$ and $t_{2}=0.04$. $\alpha$ is the $\operatorname{AR}(1)$ coefficient of the shock process, $\sigma$ is the standard deviation as a proportion of the mean GDP.

can be seen in figure 5: volatility and persistence loci are increasing in $t_{2} / t_{1}$. The effect is at its strongest at high values of $\alpha$.

Table 3: RER half-lives and the relative trade friction

\begin{tabular}{cccccc}
\hline & $\alpha=0.6$ & $\alpha=0.7$ & $\alpha=0.8$ & $\alpha=0.9$ & $\alpha=1$ \\
\hline$t_{2} / t_{1}=2$ & 1.4 & 1.9 & 2.9 & 5.0 & 263.5 \\
$t_{2} / t_{1}=4$ & 1.4 & 2.0 & 3.1 & 6.1 & 653.4 \\
$t_{2} / t_{1}=6$ & 1.4 & 2.0 & 3.1 & 6.2 & 1060.2 \\
$t_{2} / t_{1}=8$ & 1.4 & 2.0 & 3.1 & 6.2 & 1641.0
\end{tabular}

Each result is based on 2000 Monte Carlo simulations of the linear shipping cost model $\left(c_{i}=0 i=1,2\right)$ starting from $t_{1}=0.02$ and $t_{2}=0.04$. $\alpha$ is the $\operatorname{AR}(1)$ coefficient of the shock process, $\sigma$ is the standard deviation as a proportion of the mean GDP.

When both foreign and home countries are subject to endowment shocks, correlation of the two shock processes influences stochastic properties of the real exchange rate. Half lives of convergence for RER are increasing in the correlation of shocks while standard deviation of the real exchange rate is decreasing monotonically. When shocks are sector-specific, their negative correlation has a minimal impact on volatility and persistence of the real exchange rate. For positive values of the shock correlation coefficient, half life of convergence is increasing in correlation coefficient. 


\subsection{Country-specific shocks}

To isolate the effect of an additional shock process to endowments Abroad, shock persistence parameter $\alpha$ is constrained to be the same at Home and Abroad and also across goods $i$ :

$$
\hat{Y}_{i, t}=\alpha \hat{Y}_{i, t-1}+(1-\alpha) \bar{Y}+\hat{u}_{t} \text { for } i=1,2
$$

where $\hat{Y}_{i, t}=\left[\begin{array}{c}Y_{i, t} \\ Y_{i, t}^{*}\end{array}\right], \hat{u}_{t}=\left[\begin{array}{c}u_{t} \\ u_{t}^{*}\end{array}\right]$ and $\hat{u}_{t} \sim \mathrm{N}(0, \hat{\Omega})$ where $\hat{\Omega}=\left(\begin{array}{cc}\sigma^{2} & \gamma \\ \gamma & \sigma^{2}\end{array}\right)$. The correlation of shocks at Home and Abroad $\eta=\frac{\gamma}{\sigma^{2}}$ affects the properties of the real exchange rate. Persistence of the real exchange rate is lowest when the $\eta$ is close to zero (left half of figure 6). Positively correlated shocks tend to create relatively small price deviations on average which lengthens time needed to cross a threshold. Negatively correlated shocks lead to larger price deviations which lowers their persistence due to the arbitrage trade mechanism in the model. Therefore, real exchange rate persistence increases in $\eta$. On the other hand, volatility of the real exchange decreases monotonically in $\eta$. Negatively correlated shocks virtually act like a single unilateral shock of a larger magnitude, increasing volatility of real exchange rate. Positively correlated shocks lead to smaller price differences on average. Standard deviation of RER therefore approaches 0 as $\eta$ approaches 1 .

Figure 6: RER properties with country- and sector- specific endowment shocks in linear model
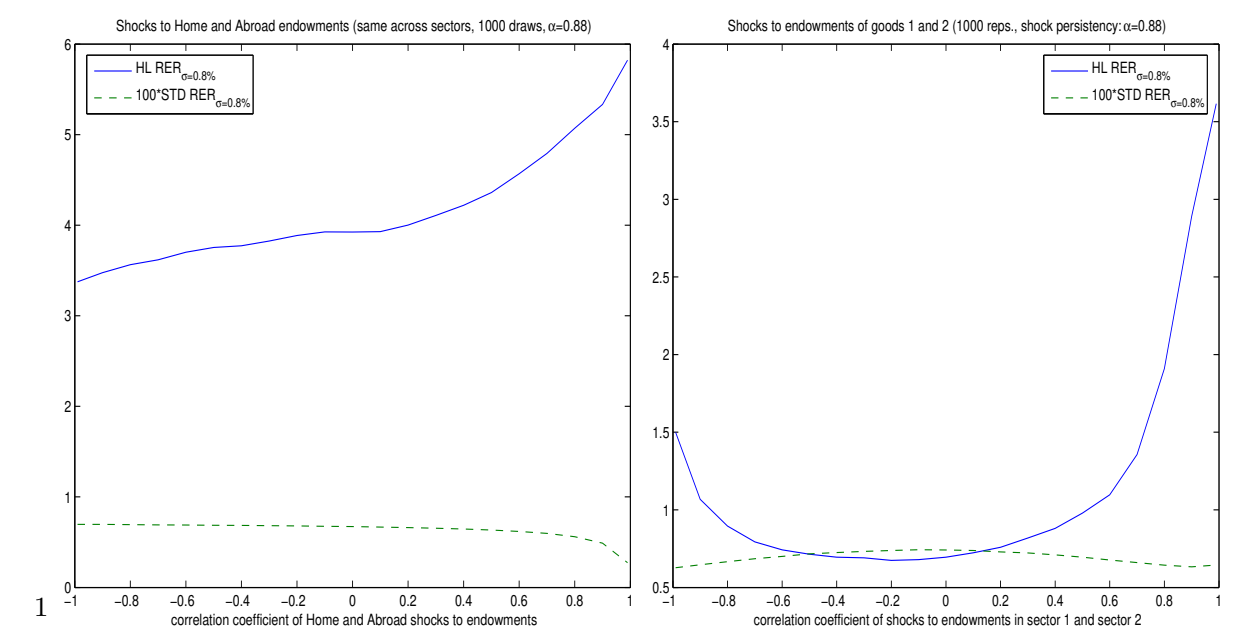

${ }^{1}$ In both simulations, shock volatility as a proportion of GDP is set to $\sigma=0.034$.

\subsection{Sector-specific shocks}

Differences in endowment shocks across goods may proxy for sector-specific productivity shocks. It is assumed that sectoral endowment shocks at Home are correlated and that there are no endowment shocks Abroad:

$$
\tilde{Y}_{t}=\alpha \tilde{Y}_{t-1}+(1-\alpha) \bar{Y}+\tilde{u}_{t} \text { for } i=1,2
$$


where $\tilde{Y}_{t}=\left[\begin{array}{c}Y_{1, t} \\ Y_{2, t}\end{array}\right], \tilde{u}_{t}=\left[\begin{array}{c}u_{1, t} \\ u_{2, t}\end{array}\right]$ and $\tilde{u}_{t} \sim \mathrm{N}(0, \tilde{\Omega})$ where $\tilde{\Omega}=\left(\begin{array}{cc}\sigma^{2} & \gamma \\ \gamma & \sigma^{2}\end{array}\right)$. The exercise is interesting for two reasons. It highlights the fact that the persistence of aggregate RER does not imply equal persistence in its components. Small RER deviations may be mean reverting because they originate from larger deviations for individual goods of opposite magnitude. Empirically, this effect has been documented by Crucini, Telmer and Zachariadis (2005). Note that this effect works in the opposite direction than the "aggregation bias" effect introduced by Imbs et. al. (2003).

Now, both persistence and standard deviation of the real exchange rate increase $\tilde{\eta}$ (right panel of figure 6). When the endowment shock to goods 1 and 2 are negatively correlated $(\tilde{\eta}<0)$, positive $\mathrm{LOPD}_{1}$ tends to be offset by a negative $\mathrm{LOPD}_{2}$ which leads to a small deviation in the real exchange rate. Yet such small RER deviations get arbitraged away because they originate in two law of one price deviations of opposite signs but large magnitudes. This effect lowers the half life of convergence of RER (this effect disappears as $\eta$ approaches zero). For $\tilde{\eta}>0$, shocks to goods 1 and 2 grow more similar and, as $\tilde{\eta}=1$, persistence of the real exchange rate approaches the value when good endowments are subject to a single shock (see table 1 above).

Standard deviation of the real exchange rate is increasing in $\tilde{\eta}$. Negatively correlated shocks tend to offset each other and lower the volatility of the real exchange rate. Positive correlation makes the two shocks resemble a single country-specific shock which moves law of one price deviations of both goods in unison, leading to a larger real exchange rate deviation. Again, as $\tilde{\eta}$ approaches 1 , RER volatility approaches the value for a single country-specific shock.

\subsection{Real exchange rate in a model with quadratic adjustment costs}

Real exchange rate in the quadratic adjustment cost model is necessarily more volatile and more persistent than in a linear shipping cost model. The additional friction of quadratic adjustment costs in changes in trade volume reduces profitability of arbitrage following an endowment shock. As we have seen in section 3.1.1, no-trade zones in the one-period QAC model are identical to those in a linear shipping cost model (these only depend on $t_{1}$ and $t_{2}$ ). However, LOPD thresholds are increasing in the size of an endowment shock, and in general exceed the shipping friction $t_{i}$. Additional costs lower the trade volume, leaving equilibrium consumption sets closer to the endowments and prices closer to autarky prices. LOPDs are larger (in excess of $t_{i}$ ) and more "sticky" as firms adjust to a profitable shock over more periods. Negative contemporaneous arbitrage profits may be optimal as firms have to balance the costs of trade deceleration with a potentially negative marginal revenue of arbitrage.

Because of the constraints of numerical solution methods, simulation results are not perfectly comparable across the models. Longer time horizons are costless in the linear cost model and can be used to increase the precision of persistence and volatility estimates. Quadratic adjustment cost model is inherently dynamic and the numerical solution method has to limit the maximum number of time periods allowed for adjustment. This makes the inference of equilibrium properties less precise. For sim- 
plicity, and to allow convergence, autoregressive endowment process in the quadratic adjustment cost model is only shocked in the first period ${ }^{14}$.

A $T$-period simulation is repeated $M$ times. At the end of each simulation, estimates of Half-life and volatility of the real exchange rate are collected. Means of this distribution are reported in the tables below ${ }^{15}$. The endowments follow $Y_{i, t}=$ $\alpha Y_{i, t-1}+(1-\alpha) \bar{Y}+u_{t} i=1,2$ where $u_{t} \sim \mathrm{N}\left(0, \sigma^{2}\right)$, assuming that $u_{t}=0$ for $t>1$.

Table 4: Mean half-life of convergence for $\log (\mathrm{RER})$ when $\mathrm{c}=0.1$

\begin{tabular}{ccccc}
\hline & $\alpha=0.7$ & $\alpha=0.8$ & $\alpha=0.9$ & $\alpha=0.99$ \\
\hline$\sigma=0.8 \%$ & 1.9444 & 3.12 & 7 & - \\
$\sigma=1.9 \%$ & 1.9438 & 3.11 & 6.8 & - \\
$\sigma=3.4 \%$ & 1.9436 & 3.11 & 6.7 & - \\
$\sigma=6.8 \%$ & 1.9433 & 3.1 & 6.6 & - \\
\hline
\end{tabular}

Each result is based on 1000 simulations of the model when $T=20, t_{1}=0.0054$ and $t_{2}=0.0174$ are the shipping trade frictions (see Calibration section 5). $\alpha$ is the $\operatorname{AR}(1)$ coefficient of the shock process.

As in the linear cost model, half life of convergence decreases in $\sigma$ and increases in $\alpha$ (see tables 4 and 6 ). The adjustment costs matter mainly for volatility: the rate at which convergence speed declines in $\sigma$ is much slower compared to the linear shipping cost model. Speed of convergence can not be computed for $\alpha$ close to 1 because of of the limited time for adjustment. Because adjustment costs lower the speed of adjustment, half lives are longer for any $\alpha$ and $\sigma$.

Table 5: Mean half-life of convergence estimate of $\log (\mathrm{RER})$ when $\mathrm{c}=0.01$

\begin{tabular}{ccccc}
\hline & $\alpha=0.7$ & $\alpha=0.8$ & $\alpha=0.9$ & $\alpha=0.99$ \\
\hline$\sigma=0.8 \%$ & 1.943 & 3.105 & 6.567 & 68 \\
$\sigma=1.9 \%$ & 1.9429 & 3.1048 & 6.567 & 66 \\
$\sigma=3.4 \%$ & 1.9428 & 3.1047 & 6.515 & 65 \\
$\sigma=6.8 \%$ & 1.9428 & 3.09 & 6.522 & 63
\end{tabular}

Each result is based on 100 simulations of the model when $T=20, t_{1}=0.0054$ and $t_{2}=0.0174$ are the shipping trade frictions (see Calibration section 5). $\alpha$ is the $\operatorname{AR}(1)$ shock coefficient.

Volatility of real exchange rate is higher for any $\alpha$ and $\sigma$ than in the linear shipping cost model (see Table 6). Unlike in the linear shipping cost model, estimates of real exchange rate volatility relative to that of the GDP are not sensitive to endowment volatility, as more volatile endowments lead to higher volatility in prices, keeping the ratio unchanged. The standard deviation estimates decline in $\alpha$ because of a smoother adjustment in prices imposed by the quadratic adjustment costs.

\footnotetext{
${ }^{14}$ If the $\mathrm{AR}(1)$ endowment process is shocked in every period, numerical solver may not converge because the assumption of full adjustment to the equilibrium by $t=T$ imposes unrealistically fast adjustment, especially in the latter periods.

${ }^{15}$ This contrasts with the result tables for the linear shipping cost model which report one statistic based on a simulation of a considerably longer length.
} 
Table 6: $[$ Mean std $(\log ($ RER $))] /[$ Mean $\operatorname{std}(\log ($ GDP $))]$ when $\mathrm{c}=0.1$

\begin{tabular}{ccccc}
\hline & $\alpha=0.7$ & $\alpha=0.8$ & $\alpha=0.9$ & $\alpha=0.99$ \\
\hline$\sigma=0.8 \%$ & 27.62 & 14.39 & 12.59 & 8.49 \\
$\sigma=1.9 \%$ & 17.83 & 14.88 & 12.35 & 8.42 \\
$\sigma=3.4 \%$ & 17.68 & 14.52 & 12.24 & 8.54 \\
$\sigma=6.8 \%$ & 17.07 & 14.25 & 12.14 & 8.75
\end{tabular}

Each result is based on 1000 simulations of the model when $T=20, t_{1}=0.0054$ and $t_{2}=0.0174$ are the shipping trade frictions (see Calibration section 5). $\alpha$ is the $\operatorname{AR}(1)$ shock coefficient.

Table 7: $[$ Median $\operatorname{std}(\log ($ RER $))] /[$ Median $\operatorname{std}(\log ($ GDP $))]$ when $\mathrm{c}=0.1$

\begin{tabular}{ccccc}
\hline & $\alpha=0.7$ & $\alpha=0.8$ & $\alpha=0.9$ & $\alpha=0.99$ \\
\hline$\sigma=0.8 \%$ & 1.951 & 1.952 & 1.953 & 2.03 \\
$\sigma=1.9 \%$ & 1.950 & 1.951 & 1.952 & 2.08 \\
$\sigma=3.4 \%$ & 1.950 & 1.950 & 1.951 & 2.36 \\
$\sigma=6.8 \%$ & 1.949 & 1.949 & 1.950 & 2.71
\end{tabular}

Each result is based on 1000 simulations of the model when $T=20, t_{1}=0.0054$ and $t_{2}=0.0174$ are the shipping trade frictions (see Calibration section 5). $\alpha$ is the $\operatorname{AR}(1)$ shock coefficient.

\section{Calibration}

In this section I describe the parameter choices for the calibration of the model. I choose the utility function weights symmetrically: $\gamma_{i}=\frac{1}{3} \forall i$. The inverse of the elasticity of substitution $\theta$ assumes the standard value in the literature 1.5 (see Chari, Christiano \& Kehoe (1994) and McGrattan (1994)).

Figure 7: Calibration of per-kg-per-km shipping cost for cooled sea transport

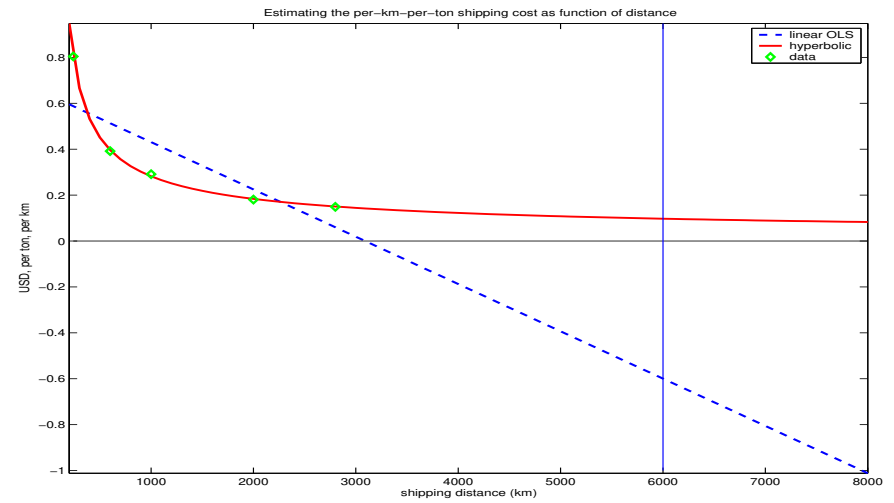

Shipping costs are calibrated directly as a tax (a heterogeneous iceberg cost) that disappears in the course of good's shipment ${ }^{16}$. I assume that, for any route, this tax depends multiplicatively on the distance and the weight of a good. Although unit shipping costs tend to decline with distance (possibly due to increasing returns to scale

\footnotetext{
${ }^{16}$ Many authors calibrate the transportation costs using indirect estimates. For an example, see Ravn \& Mazzegna (2002)).
} 
in transportation), this is not a problem here because the model has only two locations (one distance). Weight-dependance of shipping costs has been established by many (e.g., see Table 7 in Hummels (1999)). US and EU are chosen as locations because of their similar size. The distance is set equal to the New York - Hamburg shipping distance of $6000 \mathrm{~km}$. Most goods are shipped by sea between Europe and the US. I find two sources for shipping cost estimates.

In a large survey of all modes of transportation, Runhaar et. al (2001) quote an average price in 2001 for a standard 40' container on a route Rotterdam - Singapore (9650km) of NLG 3060, including a NLG 360 fuel surcharge (equal to USD 1220 in 2001). They estimate the average load of a 40' container is 16.25 ton. This yields an average rate of USD 0.0077 per ton per $\mathrm{km}$ in 2001.

Perishable goods such as most of foodstuffs are shipped in chilled containers. In a survey of shipping costs for fish containers Brox et. al. (1984) survey costs across a range of distances. The implied per ton per km shipping costs can be well approximated by a hyperbolic function (see figure 7 ). At the $6000 \mathrm{~km}$ distance these imply a unit cost of USD 0.11 per ton per km between US and Europe.

In order to compute the share of the good that is used up in transportation, I use the the dataset of physical weights and average prices in 2001 used in Berka (2002). Approximately $24 \%$ of the goods in that dataset require refrigerating for transport. Using this as a weight, the average shipping cost per ton per $\mathrm{km}$ is USD 0.033. An average weight of a good in the dataset is $43 \mathrm{~kg}$, and the average price USD 745 (2001 prices). Because I need to calibrate two fricitions, I arbitrarily pick two weights $(20 \mathrm{~kg}$ and $66 \mathrm{~kg}$ ) which equal the average weight of a good in that dataset. Consequently, the per-kg-per-km fractions $t_{i}$ of goods $i=1,2$ equal 0.0054 and 0.0174 , respectively. That is, about $0.54 \%$ of good 1 and $1.74 \%$ of good 2 get used in transportation. These cost estimates are conservative compared to most of the literature: Harrigan (1993) finds transportation barriers of 20\%. Hummels (1999) uses 2-digit SITC data to estimate a transportation costs of 9\%. Using 4-digit SITC data, Ravn \& Mazzegna (2002) find that the weighted average of transportation costs declined from $6.31 \%$ in 1974 to $3.49 \%$ in 1994 . IMF frequently uses $11 \%$ as a rule of thumb for transportation costs. All these are greater than the $1.14 \%$ average in my calibration.

The stochastic endowment process at Home is calibrated to match the logged and H-P-filtered quarterly U.S. GDP series from 1973:1 to 1994:4 (see Chari, Kehoe \& McGrattan (2002)). That implies the $\operatorname{AR}(1)$ coefficient $\alpha=0.88$ and the standard deviation of the residuals of this process is $0.8 \%$ of the mean GDP. Because the two countries in the model are approximately of the same size, the output process Abroad is calibrated to the total GDP of the main EU members: France, Italy, UK and Germany. From Chari, Kehoe \& McGrattan (2002), this implies a correlation between the two output processes $\operatorname{corr}\left(Y, Y^{*}\right) \equiv \hat{\eta}=\frac{\gamma}{\sigma^{2}}=0.6$. The mean endowment of each good is normalized to 100.

Calibration of the quadratic adjustment cost parameter $c$ appear in the literature. I aim to calibrate $c$ implicitly by matching the co-movement of consumption vectors between the two countries. I find that such value has to lie between $c=0.05$ and $c=0.1$. We know from section 4.4 that RER persistence increases in $c$, as will the standard deviation of RER relative to GDP. At the same time, thresholds of law of 
one price deviations are still distinctly different between the two goods for these levels of adjustment cost parameter $c$.

\section{Simulation results}

\subsection{Simulation results in a linear shipping cost model}

A bivariate vector of 10,000 normally distributed shocks is used to generate the stochastic endowment vectors at Home and Abroad: $\hat{Y}_{i, t}=\alpha \hat{Y}_{i, t-1}+(1-\alpha) \bar{Y}+\hat{u}_{t}$ for $i=1,2$ where $\hat{Y}_{i, t}=\left[\begin{array}{c}Y_{i, t} \\ Y_{i, t}^{*}\end{array}\right], \hat{u}_{t}=\left[\begin{array}{c}u_{t} \\ u_{t}^{*}\end{array}\right]$ and $\hat{u}_{t} \sim \mathrm{N}(0, \hat{\Omega})$ where $\hat{\Omega}=\left(\begin{array}{cc}\sigma^{2} & \gamma \\ \gamma & \sigma^{2}\end{array}\right)$. The model is then solved for equilibrium price levels and allocations. The solution can be described qualitatively in the same way as in section 2.4. Good 1 is traded more frequently ( $86 \%$ of the time periods) than good 2 (32\%) (see Figure 15). Distribution of law of one price deviations in Figure 16 is clearly bimodal, with peaks corresponding to thresholds. Table 8 summarizes selected statistics.

Table 8: Properties of the US-EU model simulation

\begin{tabular}{|c|c|c|c|c|c|}
\hline & data & $\begin{array}{c}\text { linear } \\
\text { model }^{1}\end{array}$ & $\begin{array}{c}\mathrm{QAC} \\
c=0.05\end{array}$ & $\begin{array}{l}\text { model }^{2} \\
c=0.1\end{array}$ & $\mathrm{CKMcG}^{3}$ \\
\hline \multicolumn{6}{|l|}{ Autocorrelations } \\
\hline \multicolumn{6}{|l|}{ Ex. rates \& prices } \\
\hline RER & 0.83 & 0.8286 & 0.868 & 0.92 & 0.62 \\
\hline \multicolumn{6}{|l|}{ Business cycle stat } \\
\hline GDP & 0.88 & $0.88^{*}$ & $0.88^{*}$ & $0.88^{*}$ & 0.62 \\
\hline Consumption & 0.89 & 0.88 & 0.854 & 0.69 & 0.61 \\
\hline Net Exports & 0.82 & 0.87 & 0.700 & 0.49 & 0.72 \\
\hline \multicolumn{6}{|l|}{ STD rel. to GDP } \\
\hline \multicolumn{6}{|l|}{ Ex. rates $\&$ prices } \\
\hline RER & 4.36 & 0.002 & $6.41(1.65)$ & $7.66(2.17)$ & 4.27 \\
\hline \multicolumn{6}{|l|}{ Business cycle stat } \\
\hline Consumption & 0.83 & 0.75 & 1 & 1 & 0.83 \\
\hline Net Exports & 0.11 & 0.19 & 0.001 & $0.001(0.49)$ & 0.09 \\
\hline \multicolumn{6}{|l|}{ Cross-Correlat. } \\
\hline GDPs & 0.6 & $0.6^{*}$ & $0.6^{*}$ & $0.6^{*}$ & 0.49 \\
\hline Consumptions & 0.38 & 0.62 & 0.283 & 0.27 & 0.49 \\
\hline NX \& GDP & -0.41 & -0.03 & 0.050 & $0.04(0.87)$ & 0.04 \\
\hline RER \& GDP & 0.08 & 0.69 & -0.02 & 0.13 & 0.51 \\
\hline RER \& NX & 0.14 & $0.88(-0.02)$ & 0.027 & 0.024 & -0.04 \\
\hline RER \& Relat. C & -0.35 & 0.96 & 0.956 & 0.95 & 1.00 \\
\hline
\end{tabular}

1 based on 10,000 simulations of the linear shipping model with parameter calibration as described in section 5.
2 based on 5,000 simulations (each 20 periods long) of the quadratic adjustment cost model with $c=0.1$.
3 results of the model simulation in Chari, Kehoe \& McGrattan (2002). 


\subsubsection{Persistence}

Linear model's logarithm of the real exchange rate matches the persistence in the data, as in Chari, Kehoe \& McGrattan (2002) (see section 5 above). Model's AR(1) estimate is $\hat{\alpha}=0.8286$ with a standard error 0.0056 , implying a half-life of convergence of about 3.7 quarters. The persistence coefficient of the real exchange rate found in the data is 0.83. Deviations from parity for good 1 are more persistent than for good 2 (AR(1) estimates of 0.7379 vs. 0.847 , respectively). Persistence of consumption and net exports in the model is driven by the persistence of the stochastic endowment process.

\subsubsection{Comovements}

The relatively small amount of trade makes consumption vectors at Home and Abroad co-move in the same way the GDPs. In a real model, good with the lowest friction has to flow in the opposite direction than other traded goods in order for the aggregate constraint to be satisfied ${ }^{17}$. While exports of goods 1 and 2 are positively correlated with Home GDP, $\operatorname{corr}\left(N_{3}, Y\right)$ is negative. Consequently, total net exports from Home have a correlation with GDP close to 0 (-0.03 in the model and -0.41 in the data).

Thresholds provide a partial disconnect of the real exchange rate from the real economy. A sufficiently large endowment change lowers the price at Home relative to Abroad - a depreciation (increase) in the real exchange rate that leads to a positive $\operatorname{corr}(R E R, Y)^{18}$. The expenditure-switching effect of the real exchange rate in the model can not account for the Backhus-Smith puzzle. Partial expenditure switching brings model's correlation of RER and relative consumptions away from unity and closer to the data $\left(\operatorname{corr}\left(R E R, C / C^{*}\right)=0.91\right.$ in the model and -0.35 in the data). Hence, individual good's consumption correlation between countries is negatively related to trade friction of that good: -1 for good 3, 0.834 for good 1 and to 0.686 for good 2 .

\subsubsection{Volatility}

The risk-sharing role of international trade lowers consumption volatility relative to that of endowments, bringing it slightly below that of data $(\operatorname{std}(C) / \operatorname{std}(Y)=0.75$ vs. 0.83). Trade volatility in then necessarily slightly higher than in the data $(\operatorname{std}(N) / \operatorname{std}(Y)=$ 0.19 vs. 0.11 in the data). In part, this is a result of modeling only the arbitrage motive to trade which can lead to frequently changing on/off pattern in trade volume. Inclusion of other trade motives would be desirable so as to smooth trade volume and increase volatility of consumption.

The linear shipping cost model fails to generate sufficient volatility in the real exchange rate, for several reasons. First, the adjustment to shock is instantaneous. Second, maximal deviation is a weighted average of the the trade friction of the real exchange rate's components $(0.76 \%=(0.54 \%+1.74 \%+0 \%) / 3)$. A more realistic model would allow adjustment over a longer time horizon as well as inclusion of services with

\footnotetext{
${ }^{17}$ When goods 1 and 2 do not flow in the same directions, net flow of good 3 depends on the prices of goods 1 and 2 and the volume of trade.

${ }^{18} \operatorname{corr}(R E R, Y)=0.69$ in the model but only 0.08 in the data
} 
potentially very large trade frictions ${ }^{19}$. Finally, in the absence of nominal and real rigidities, volatility of the price aggregates is limited by the volatility of the driving force of the model (see Figure 17), which is calibrated as $0.8 \%$ of GDP.

\subsection{Simulation results in a quadratic adjustment cost model}

The additional trade adjustment friction brings countries closer to their autarkic consumption $\operatorname{sets}^{20}$ and leaves the equilibrium prices further away from parity for a longer time. Therefore, both persistence and volatility of the real exchange rate increase compared to the results of a linear shipping cost model. Trade volume declines and becomes smoother, with consumption closely mimicking the endowment dynamics.

\subsubsection{Persistence}

On average, real exchange rate is more persistent in the QAC model than in the data, with an $\operatorname{AR}(1)$ coefficient estimate of 0.92 when $c=0.1$ and 0.868 when $c=$ 0.05. Higher persistence is a result of upward-sloping thresholds in the law of one price deviations. Consumptions and trade are persistent to a lesser degree than the endowments due to trade smoothing role.

\subsubsection{Volatility}

The calibration of the quadratic adjustment cost model is significantly more successful in creating volatility of prices relative to GDP (see table 8). The average standard deviation estimate of 7.66 is well above the 4.35 found in the data (when $c=0.05$, volatility is 6.4 times higher than that of GDP). Histogram of all standard deviation estimates can be found in Figure 24. Law of one price deviations for good 1 are more volatile than that of the real exchange rate. As can be seen in Figure 21, volatility of the law of one price deviation for good 2 is only marginally higher than for good 1 at $c=0.1$ (see Figure 25). The distribution of mean law of one price deviations appears to be bimodal with higher mass near the thresholds (figure 25). The bimodality is not as pronounced as in the linear model.

Volatility of the consumption aggregate is higher as the economies are more disconnected in the QAC model. On the flip side, small trade volume leads to insufficient volatility of net exports. Consumption co-movement between the countries in the model (cross-correlation of 0.28 ) is closer to the data (0.38) than it was in the case linear shipping costs model (0.62).

\footnotetext{
${ }^{19}$ Nominal rigidities could also serve to increase the volatility of price aggregates over that of the endowment shocks. Yet unlike quadratic adjustment costs, nominal rigidities would be orthogonal to the current workings of the model.

${ }^{20}$ This happens in a more complicated way than by "increasing the distance" as would be the case in a linear shipping model (see section 3.1.1).
} 


\section{Conclusions and extensions for future research}

Geography and physics delimit our lives but are somewhat marginalized in economic analysis. In a vast majority of cases, this is a justifiable omission due to a static nature of these constraints and a uniform way in which they are thought to affect economic variables. However, there are cases when geography and physics affect the marginal decisions in an economically relevant way. This paper analyzes a particular example the persistence and volatility dimensions of the purchasing power parity puzzle.

The persistence in deviations of the real exchange rate - and of prices of traded goods from parity - need not be puzzling. It can be explained as a byproduct of heterogeneous trade costs. This idea is intuitive and empirically relevant (e.g., Berka 2002). Nominal rigidities may not be necessary in explaining persistence and volatility in price differences across countries. Conversely, this model can be thought of as justifying an optimal level of nominal price stickiness as a byproduct of the shipment costs which depend on distance and physical characteristics of goods.

Because weight and volume of products matter in shipment (in a way which is unrelated to their price) differences in physical characteristics leads to a heterogeneity in the unit shipping costs.

This paper studies two general equilibrium models in which trade between countries arises due to arbitrage opportunity for any particular good. Goods are heterogeneous in a physical characteristic relevant for shipment, leading to heterogeneous trade frictions. In both models, tradability of a good is endogenously determined from the size of the difference in endowments of goods between countries and, consequently, the autarkic price difference. Price deviations in excess of the shipping costs are arbitraged away. Goods with a larger trade friction need a larger deviation from parity to become traded and are traded relatively less frequently.

In both models, real exchange rate exhibits persistent deviations from parity that arise from trade frictions. Calibration exercise shows that half life in real exchange rate deviations can match the estimates observed in the data. The linear model also generates a quantitatively close match to the persistence and co-movements of various price- and quantity- constructs. However, volatility of price deviations is insufficient.

Arbitrage firms in the second model also have to pay a quadratic adjustment cost if they change their volume of trade from one period to the next. The aim of this assumption is to avoid the unrealistic instantaneous adjustment of trade in the linear model in the same period in which endowment shock occurs. Adjustment costs can arise from additional legal and infrastructure expenses as well as other search costs and are aimed to capture the time dimension of shipping. While the core features of the linear shipping cost model stay unchanged, a dynamic and highly non-linear environment emerges. Firms' aversion to react strongly to endowment shocks by large trade volume adjustments creates more pronounced and long-lived real exchange rate deviations. This further limits the arbitrage trade between countries and the co-movement between their consumptions. Simulation results of the second model can easily match both persistence and volatility of the real exchange rate while giving qualitatively meaningful results along other dimensions. Persistence and volatility of the real exchange rate need not be puzzling, they can be explained as a result of trade costs. 
We know that prices, like trade volumes, exhibit an apparent "border effect" anomaly when comparing equidistant locations. When border exists between locations, price volatility and persistence appears to be much higher than for equidistant locations within the same country (see, i.a., Engel \& Rogers (1996) and Jenkins \& Rogers (1995)). Models in this paper can not distinguish transport costs between locations within the same country and across countries. A three-location model would allow differentiation between intra- and inter-national costs of arbitrage trade (tariffs, language, legal, culture and other barriers). Such addition may contribute to our understanding of Engel \& Rogers (1996) findings and is left for future research.

More generally, an extension of the model into a multi location (country) framework could improve our understanding of trade flows, bilateral exchange rate persistence and volatility and perhaps other multilateral economic phenomena. It is in particular possible to envision an extension of the model in which trade technology exhibits increasing returns to scale which could, in multi-location framework, help explain the "missing trade" puzzle. It may also be feasible to link the trade costs to development: should country A be producing goods that are more costly to transport than goods produced by country B, subset of prices in country A will be more isolated from some "world shocks" leading to lower integration into the world economy. If we assume that price response is desirable and that country $\mathrm{A}$ is poorer than country B (both of which are not unlikely), such a version of the model could be understood as a traderelated source of a development trap. On the empirical side, a multi country estimation framework could be used to analyze the persistence and volatility of price deviations for bilateral pairs of goods across many countries (in the same way Engel and Rogers (1996) do for city data using linear models).

\section{A Appendix: Approximating the absolute value func- tion}

As mentioned in section (3.2), function $g\left(N_{i, t}\right) \equiv I\left(\widehat{N}_{i, t}\right)=\frac{2}{\pi} \arctan \left(\lambda N_{i, t}\right)$ approximates a step function in the volume of trade $N_{i, t}$. An inverse of a trigonometric function $\tan (x), \arctan (x)$ has a range of $[-\pi / 2, \pi / 2]$ for $x \in \mathbf{R}$ and is monotonically increasing, continuously differentiable, and has a convenient property that $\arctan (x)<0$ when $x<0, \arctan (x)>0$ when $x>0$ and $\arctan (x)=0$ when $x=0$. Because of the bounded range, and because $\arctan (\lambda x)_{x=0}=0 \forall \lambda$, $\arctan (\lambda x)$ can reach the bounds very quickly. Finally, if we premultiply the function by $2 / \pi$, the range becomes $[-1,1]$ - very convenient for a step function.

The choice parameter $\lambda$ is inversely related to the approximation error, a relationship that can be seen in figure (18). However, it is misleading to use this approximation to describe the first order conditions of a system with $\left|N_{i, t}\right|$ because the absolute value function is not differentiable at 0 . Therefore, a smooth approximation $G\left(N_{i, t}\right)$ to $\left|N_{i, t}\right|$ needs to be constructed first, and then differentiated. Conveniently, function

$$
G\left(N_{i, t}\right) \equiv \int g\left(N_{i t}\right)=\frac{2}{\pi}\left[\lambda N_{i, t}\left(\frac{2}{\pi} \arctan \left(\lambda N_{i, t}\right)-0.5 \log \left(1+\left(\lambda N_{i, t}\right)^{2}\right)\right)\right]
$$


can be used to arbitrarily closely approximate $\left|N_{i, t}\right|$ by a choice of $\lambda$ (see figure (8)).

Figure 8: Approximating functions $g(N)$ and $G(N)$ for $\lambda=10^{5}$.
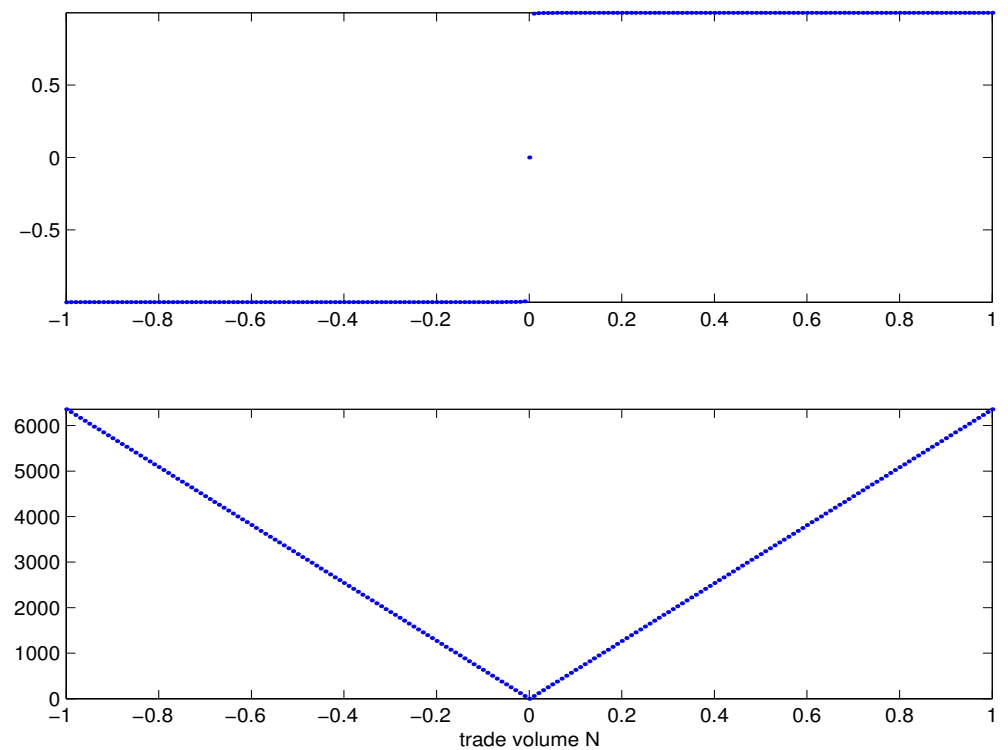

\section{B Appendix: Derivation of equation (23)}

$$
\begin{aligned}
N= & N_{-1}+\frac{1}{2 c}\left(p^{*}-p-\mathrm{I}(N) t\right) \\
\text { therefore } \partial N_{i} / \partial Y_{i}= & \frac{1}{2 c}\left(\partial p^{*} / \partial Y_{i}-\partial p / \partial Y_{i}-t\right) \pi+0(1-\pi) \text { where } \pi \equiv \operatorname{prob}\left(\left|p^{*}-p\right|>t\right) \\
\text { Noting that } p^{a u t}= & {\left[\frac{Y_{i}}{Y_{3}} \frac{\gamma_{3}}{\gamma_{i}}\right]^{-\frac{1}{\theta}} \Rightarrow \partial p / \partial Y_{i}=-\frac{1}{\theta}\left[\frac{Y_{i}}{Y_{3}} \frac{\gamma_{3}}{\gamma_{i}}\right]^{-\frac{1}{\theta}-1} \frac{1}{Y_{3}} \frac{\gamma_{3}}{\gamma_{i}} } \\
\text { and that } & \partial p^{*} / \partial Y_{i}=0 \\
\partial N / \partial Y_{i}= & \frac{\pi}{2 c \theta}\left(\left[\frac{Y_{i}}{Y_{3}} \frac{\gamma_{3}}{\gamma_{i}}\right]^{-\frac{1}{\theta}-1} \frac{1}{Y_{3}} \frac{\gamma_{3}}{\gamma_{i}}-t \theta\right), \text { identical to equation (23) }
\end{aligned}
$$

Assuming that the shares of 3 goods in the utility function are identical $\left(\gamma_{i}=\right.$ $\left.\gamma_{j} \forall i, j\right), \partial N_{i} / \partial Y_{i}<1$ when c is sufficiently large.

$$
c>\bar{c} \equiv \max \left\{0, \frac{\pi}{2 \theta}\left(\frac{Y_{i}^{-\frac{1}{\theta}-1}}{Y_{3}^{-\frac{1}{\theta}}}-t \theta\right)\right\}
$$


which is automatically satisfied $(\bar{c}=0)$ if

$$
Y_{i}>\bar{Y}_{i} \equiv\left[\frac{Y_{3}}{(t \theta)^{\theta}}\right]^{\frac{1}{1+\theta}} \text { when exporting }
$$

When $Y_{3}=100, \theta=1.5$ and $t=0.0174$ (as in the model's calibration), $\bar{Y}_{i}=51.7$. Therefore, this condition always holds when exporting. An analogous derivation can be made for the case of imports.

\section{Figures}

Figure 9: Linear model: International trade

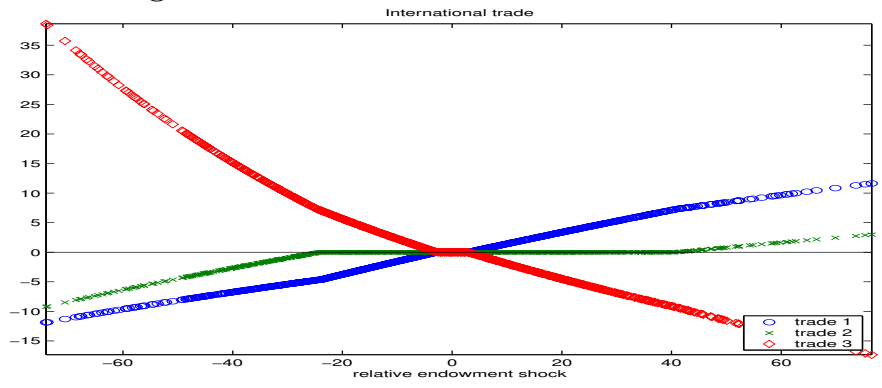

Figure 10: Linear model: means and st. dev. of LOPD as functions of shock volatility.
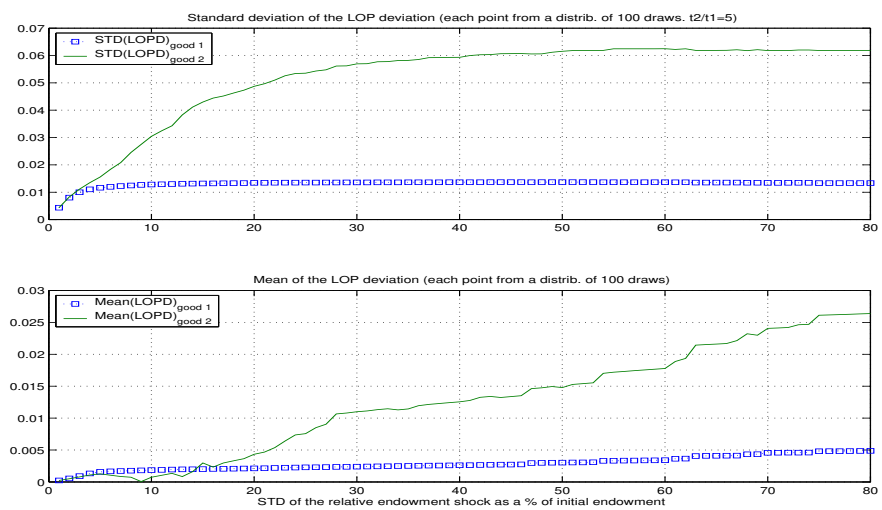
Figure 11: Linear model: average thresholds of LOPD as a function of shock volatility

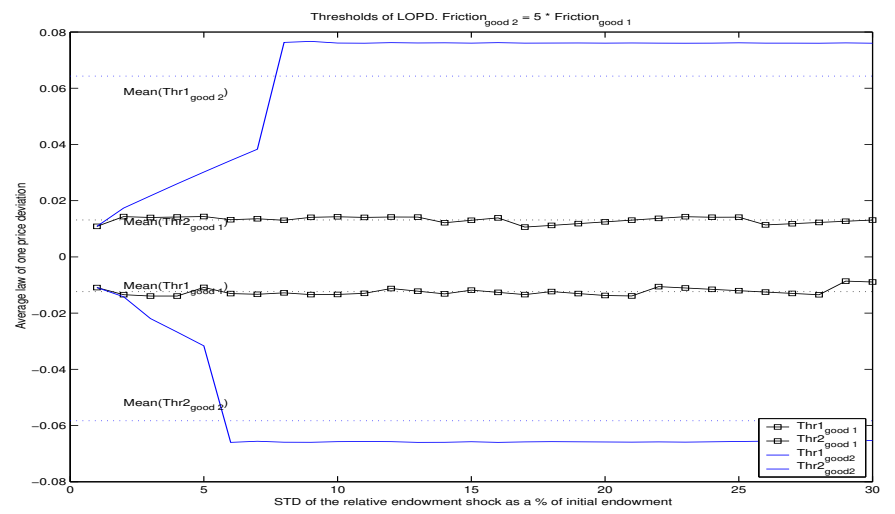

Figure 12: Linear model robustness: mean LOPD as a function of shock volatility and relative friction
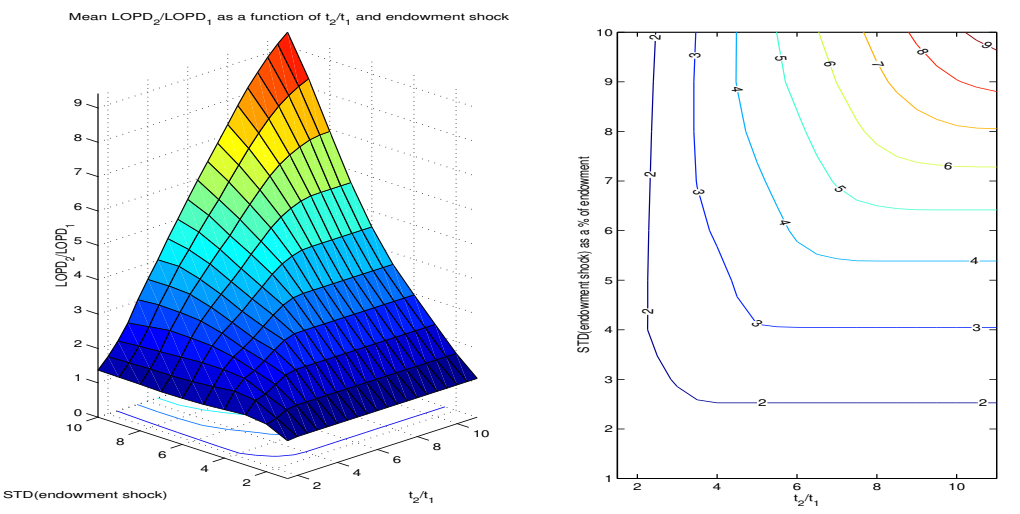

Figure 13: Linear model robustness: volatility of LOPD as a function of shock volatility and relative friction
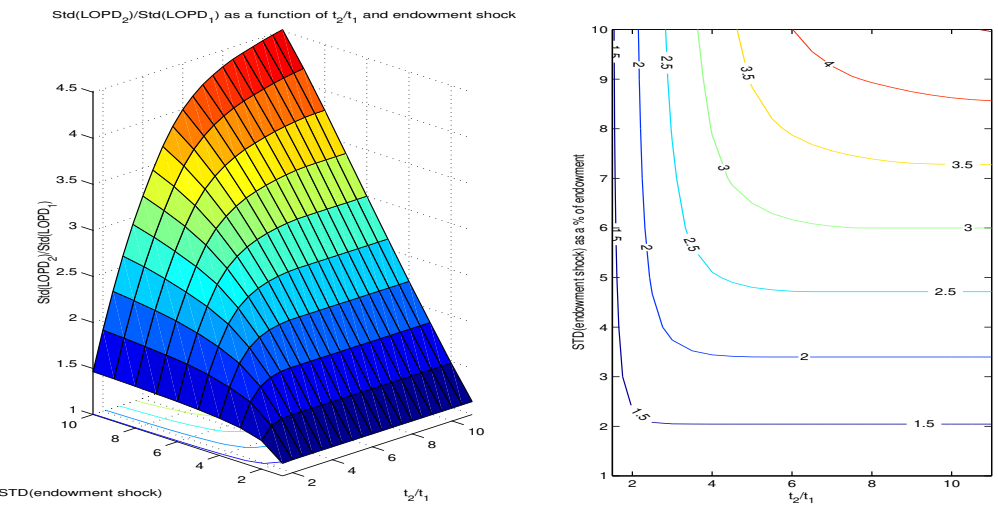
Figure 14: Linear model robustness: price deviations thresholds as a function of shock volatility and relative friction
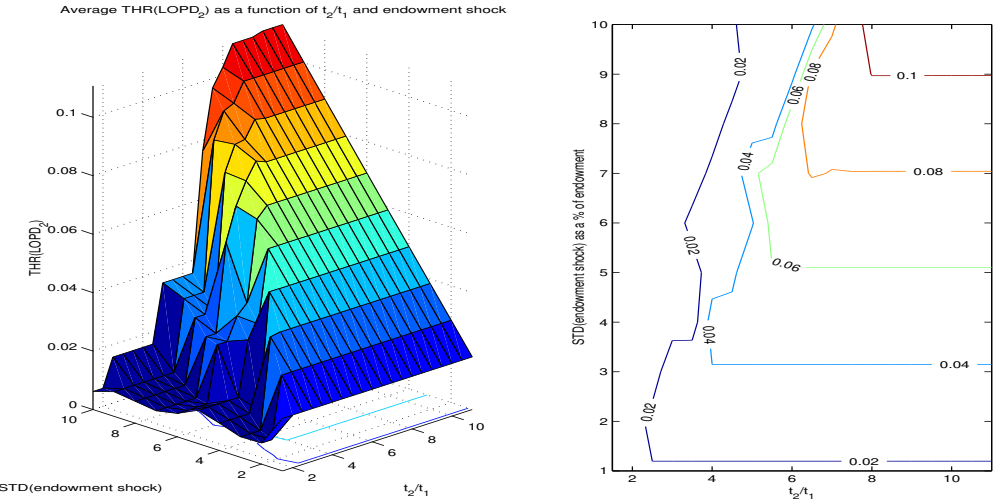

Figure 15: Distribution of trade. US-EU simulation of the linear model

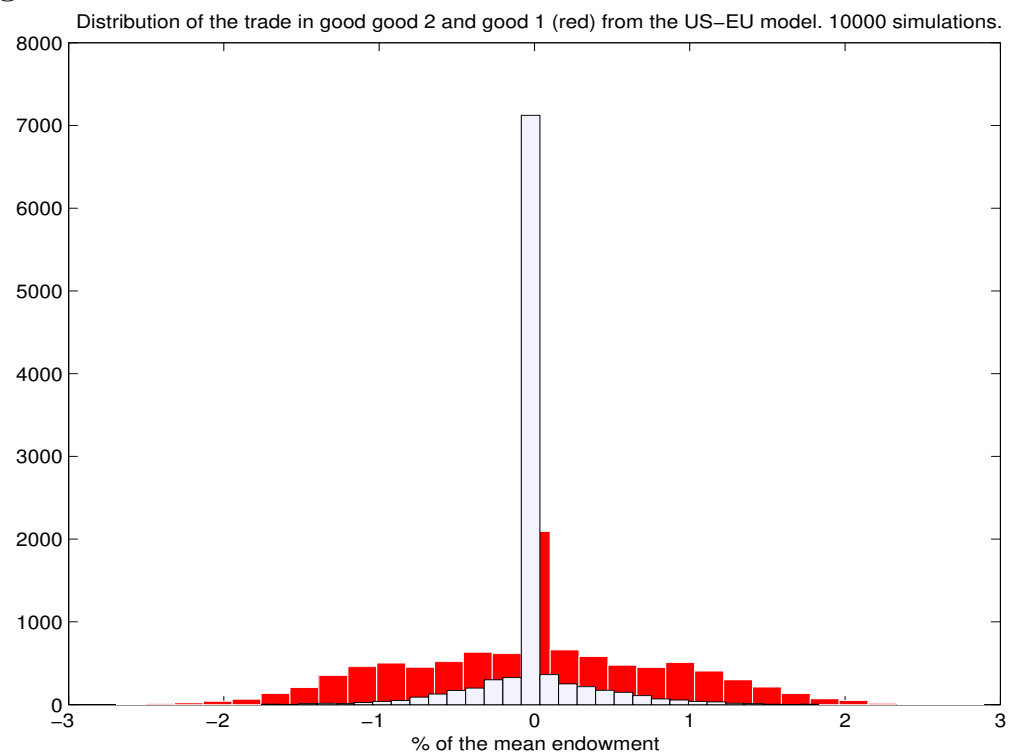

Figure 16: Distribution of international prices. US-EU simulation of the linear model

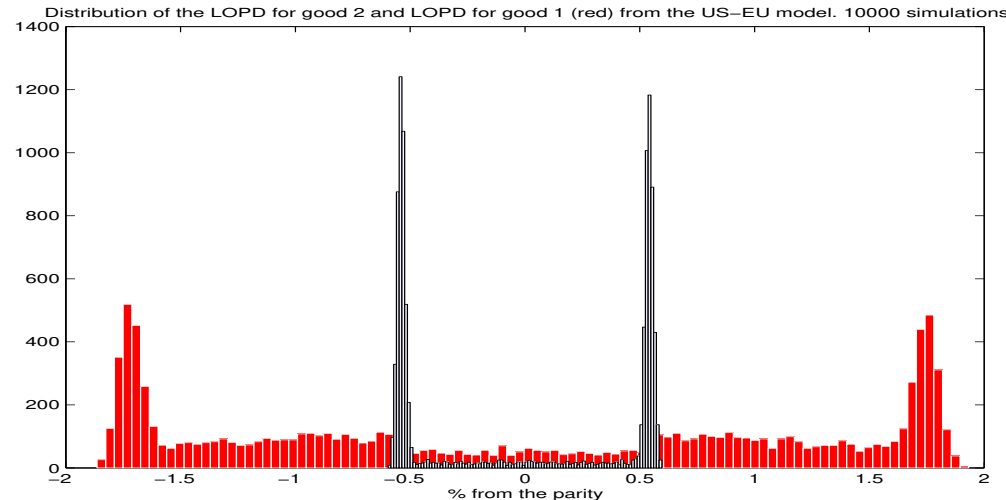


Figure 17: Distribution of RER and the shock process. US-EU simulation of the linear model

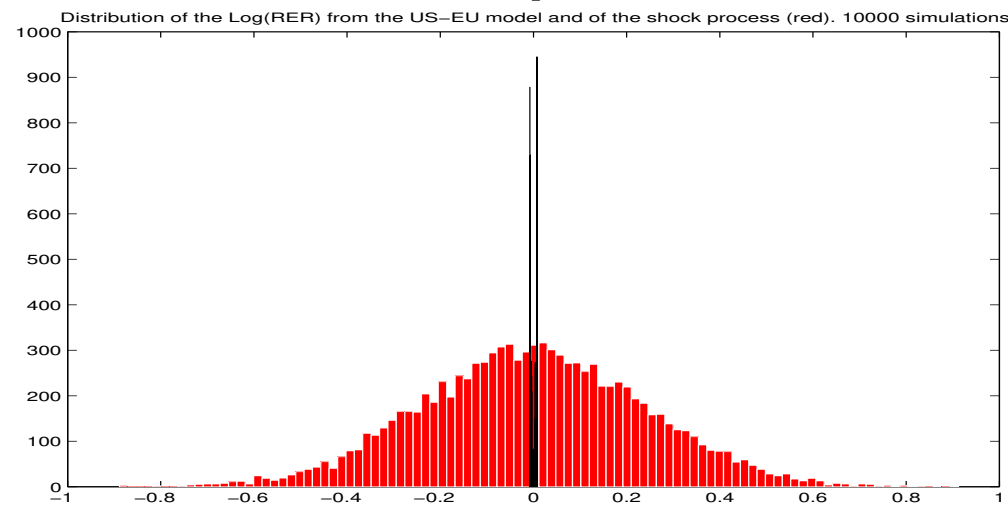

Figure 18: Approximating the indicator function in QAC model
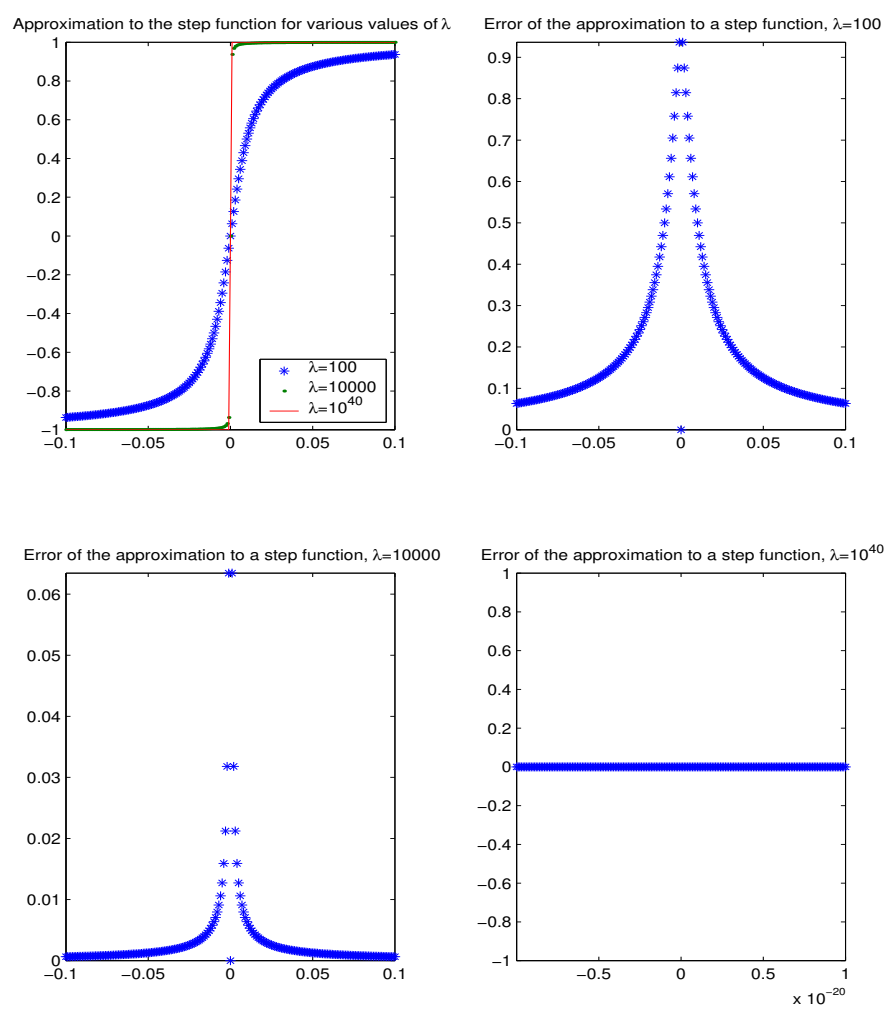
Figure 19: Thresholds in QAC model when $\mathrm{c}=0.000001$
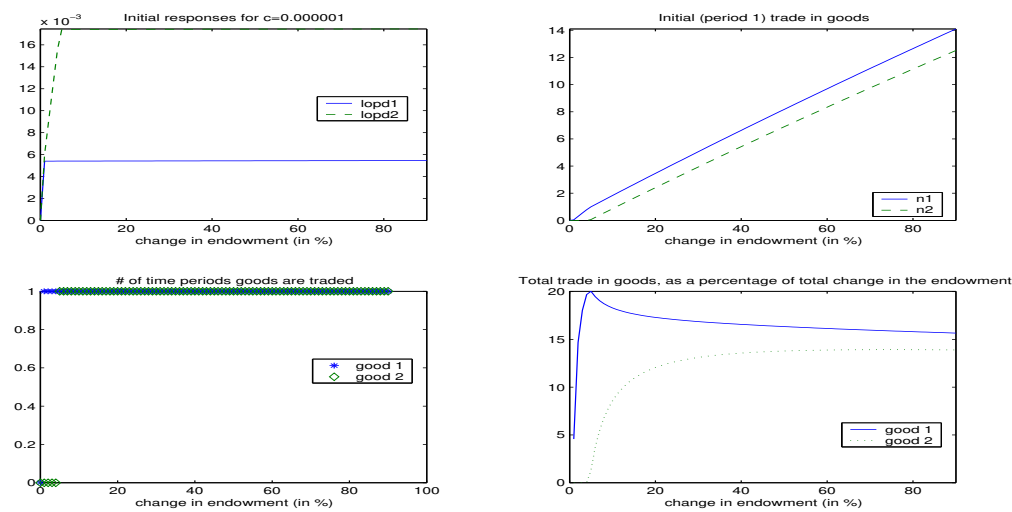

Figure 20: Thresholds in QAC model when $\mathrm{c}=0.001$
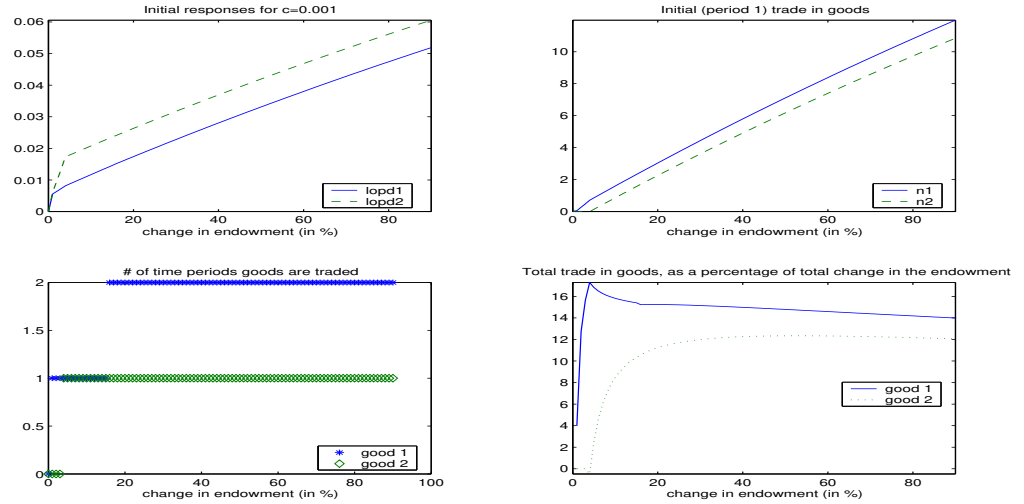

Figure 21: Thresholds in QAC model when $\mathrm{c}=0.1$
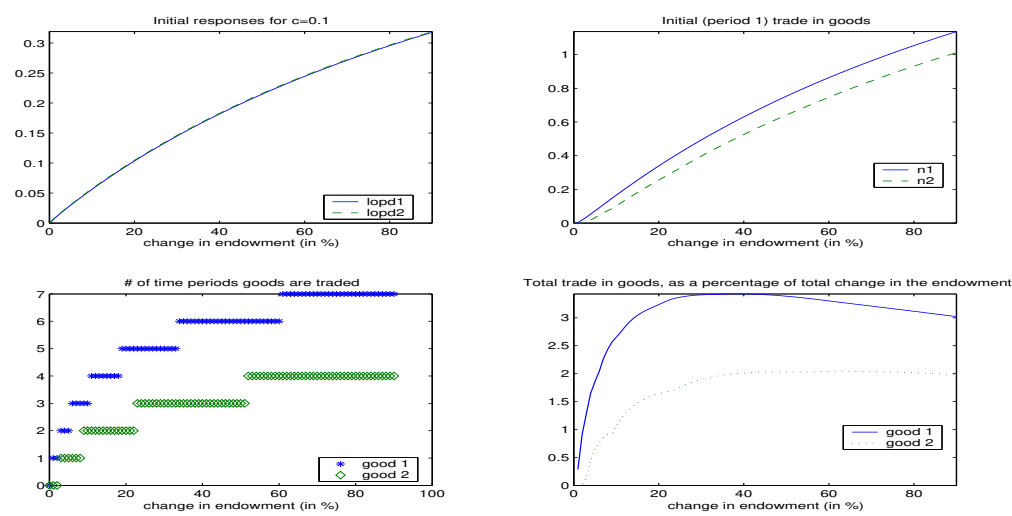
Figure 22: Thresholds in QAC model when $\mathrm{c}=1$
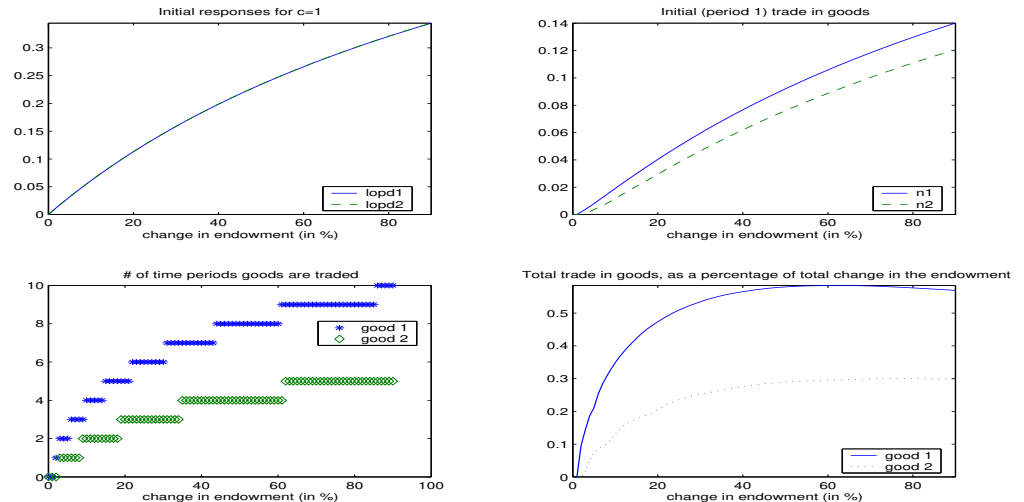

Figure 23: Profits in partial equilibrium, for various price deviations and $N_{-1} . \mathrm{c}=0.01, \mathrm{t}=0.2$

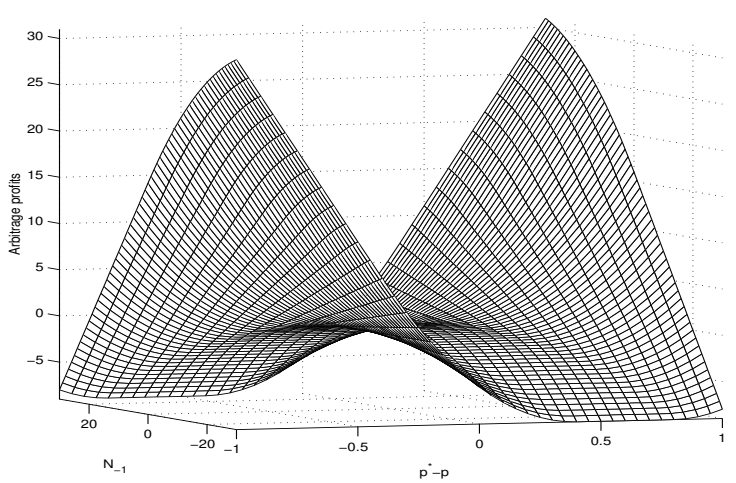


Figure 24: Distribution of standard deviation estimates in a QAC model, $\mathrm{c}=0.1$
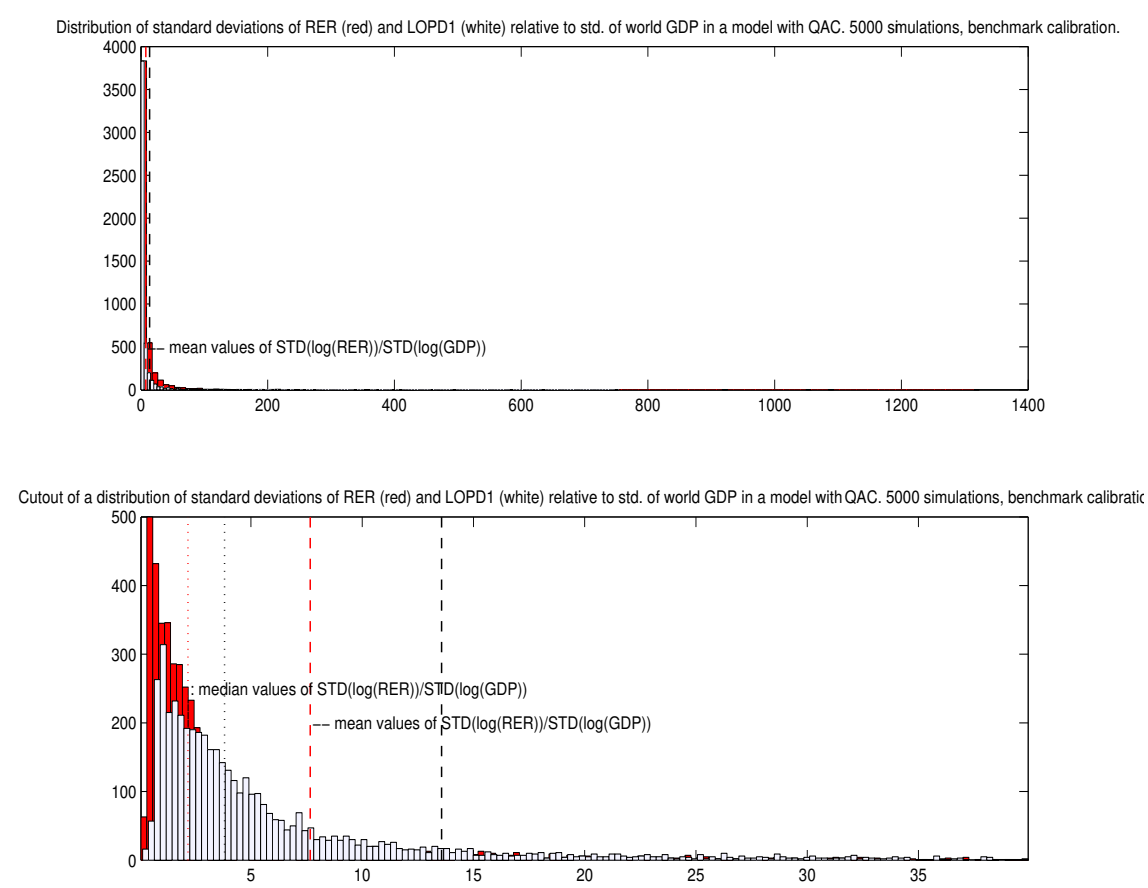

Figure 25: Price deviations in a QAC model, $\mathrm{c}=0.1$
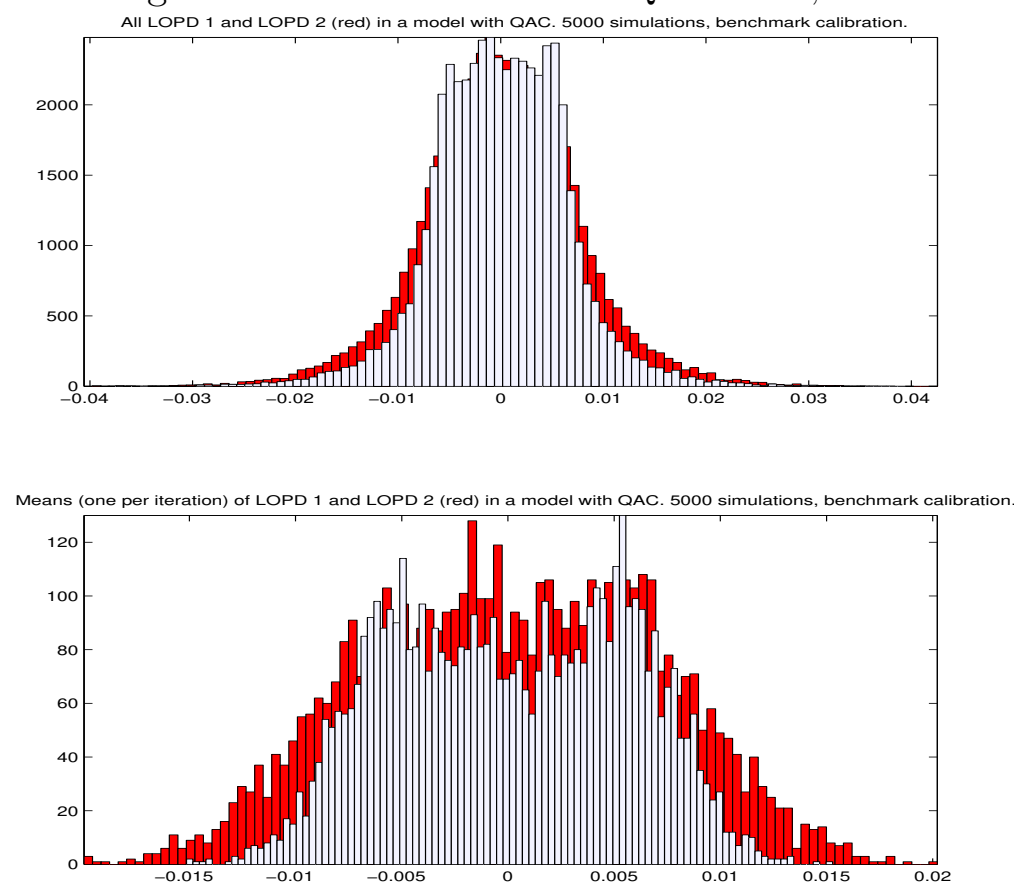
Figure 26: Endowment shocks and RER in a QAC model, c=0.1

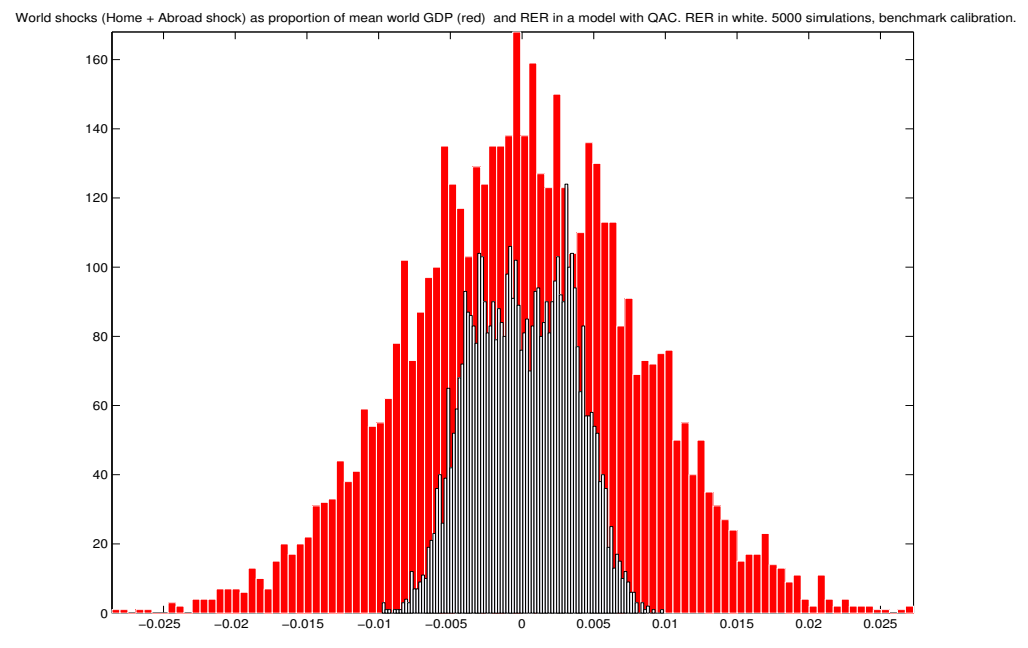

Figure 27: Trade in a QAC model, $\mathrm{c}=0.1$

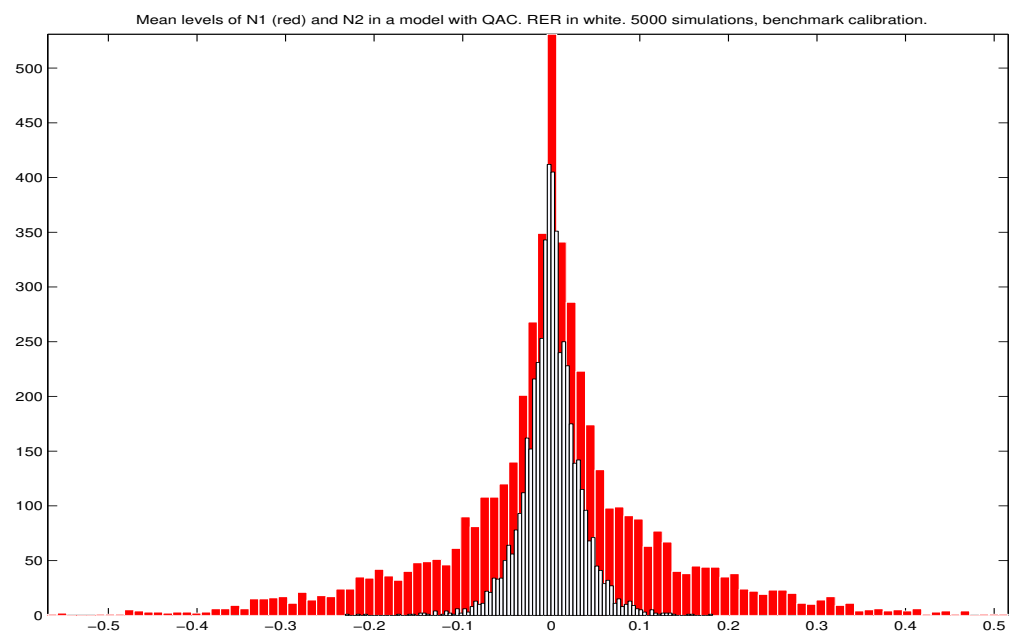

Figure 28: Consumption co-movement in a QAC model, $\mathrm{c}=0.1$
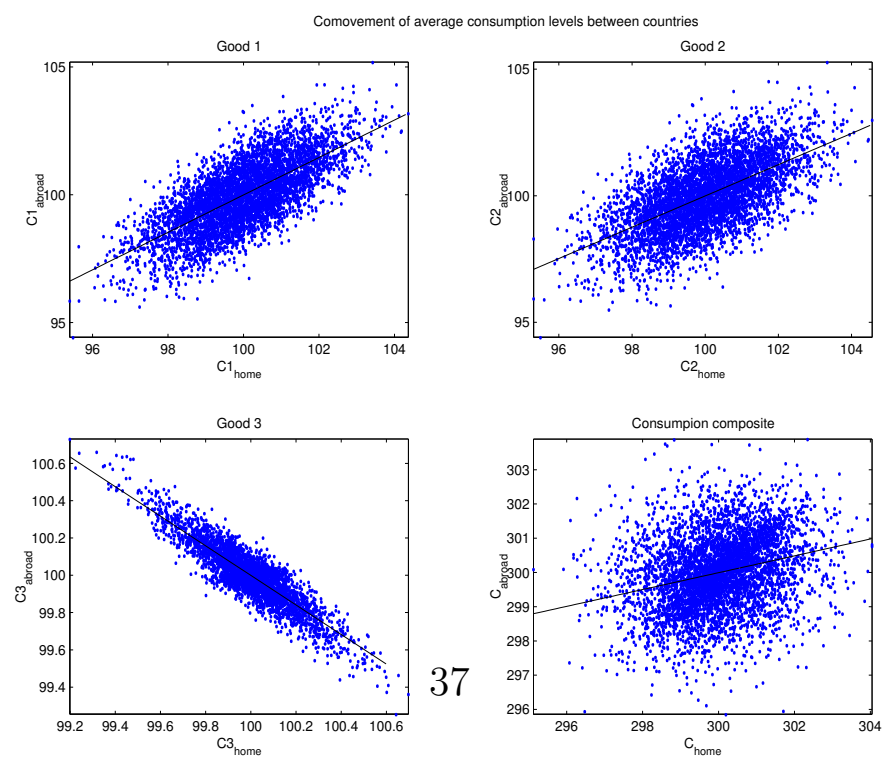


\section{References}

[1] Bela A. Balassa. The Theory of Economic Integration. Homewood, Ill., R.D. Irwin, 1961.

[2] Paul R. Bergin and Robert C. Feenstra. Pricing-to-market, staggered contracts, and real exchange rate persistence. Journal of International Economics, 54(2):333359, August 2001.

[3] Martin Berka. Non-linear adjustment in international prices and physical characteristics of goods. Manuscript, April 2002.

[4] Caroline Betts and Michael B. Devereux. Exchange rate dynamics in a model of pricing-to-market. Journal of International Economics, 50(1):215-244, February 2000 .

[5] Raouf Boucekkine. An alternative methodology for solving non-linear forwardlooking models. Journal of Economic Dynamics and Control, 19:711-734, 1995.

[6] Jan Brox, Max Kristiansen, Albert Myrseth, and Per W. Aasheim. Planning and engineering data: Containers for fish handling. Food and Agricultural Organization FAO, 1984.

[7] Ariel Burstein, Joao C. Neves, and Sergio Rebelo. Distribution costs and real exchange rate dynamics during exchange-rate-based stabilizations. Journal of Monetary Economics, 50:1189-1214, September 2003.

[8] Gustav Cassel. Abnormal deviations in international exchanges. Economic Journal, 28(112):413-415, 1918.

[9] V. V. Chari, Patrick J. Kehoe, and Ellen R. McGrattan. Can sticky price models generate volatile and persistent real exchange rates? Staff Report 277, Federal Reserve Bank of Minneapolis, Research Department, August 2002.

[10] V.V. Chari, Lawrence J. Christiano, and Patrick Kehoe. Optimal fiscal policy in a business cycle model. Journal of Political Economy, 102(4):617-52, 1994.

[11] Ehsan Choudri and Mohsin Khan. Real exchange rate in developing countries: Are Balassa-Saumelson effects present? working paper 188, IMF, October 2004.

[12] Giancarlo Corsetti and Luca Dedola. Macroeconomics of international price discrimination. Manuscript, 2002.

[13] Mario Crucini, Chris Telmer, and Marios Zachariadis. Understanding European real exchange rates. Mimeo, Vanderbilt University, Carnegie Mellon University, Louisiana State University, July 2001.

[14] Mario Crucini, Chris Telmer, and Marios Zachariadis. Understanding European real exchange rates. American Economic Review, 95(3):724-738, June 2005. 
[15] Michael B. Devereux. Real exchange rates and macroeconomics: evidence and theory. Canadian Journal of Economics, 30(4a), November 1997.

[16] Bernard Dumas. Capital market equilibrium and the real exchange rate in a spatially separated world. Review of Financial Studies, 5:153-180, 1992.

[17] Charles Engel. Accounting for US real exchange rate changes. Journal of Political Economy, 130(3):507-538, June 1999.

[18] Charles Engel and John H. Rogers. How wide is the border? American Economic Review, 86:1112-1125, 1996.

[19] James Harrigan. OECD imports and trade barriers in 1983. Journal of International Economics, 35(1-2):91-111, August 1993.

[20] David Hummels. Have international transportation costs declined? University of Chicago, July 1999.

[21] Jean Imbs, Haroon Mumtaz, Morten O. Ravn, and Helene Rey. Non linearites and real exchange rate dynamics. Journal of the European Economic Association, 1(2-3):639-649, April May 2003.

[22] Michael A. Jenkins and John H. Rogers. Haircuts or hysteresis? sources of movements in real exchange rates. Journal of International Economics, 38(3/4):339360, May 1995.

[23] Lutz Kilian and Mark P. Taylor. Why is it so difficult to beat the random walk forecast of exchange rates? Journal of International Economics, 60:87-107, May 2003.

[24] Beverly Lapham and Marianne Vigneault. National markets and international relative prices. Manuscript, July 2001.

[25] Ellen R. McGrattan. The macroeconomic effects of distortionary taxation. Journal of Monetary Economics, 33(3):573-601, 1994.

[26] Maurice Obsfeld and Kenneth Rogoff. NBER Macroeconomics Annual, chapter The six major puzzles in international macroeconomics: is there a common cause?, pages 339-390. MIT Press, 2000.

[27] Maurice Obstfeld and Alan M. Taylor. Nonlinear aspects of goods-market arbitrage and adjustment: Heckschers commodity points revisited. Journal of the Japanese and International Economies, (11):441-479, 1997.

[28] Paul G. J. O'Connel and Shang-Jin Wei. "The bigger they are the harder they fall": Retail price differences across U.S. cities. Journal of International Economics, (56):21-53, 2002.

[29] Lee E. Ohanian and Alan C. Stockman. Arbitrage costs and exchange rates. University of Rochester, November 1997. 
[30] Gauri Prakash and Alan M. Taylor. Measuring market integration: a model of arbitrage with an econometric application to the gold standard, 1879-1913. Working paper 6073, NBER, June 2001.

[31] Morten O. Ravn and Elizabetta Mazzenga. International business cycles: The quantitative role of transportation costs. Working paper 3530, CEPR, September 2002.

[32] H. A. C. Runhaar, B. Kuipers, R. van der Heijden, and W. H. Melody. Freight transport in 2010: an exploration of future prices and quality of freight transport in three scenarios. The Netherlands TRAIL Research Shool, November 2001.

[33] Piet Sercu, Raman Uppal, and Cynthia Van Hulle. The exchange rate in the presence of transaction costs: Implications for the tests of Purchasing Power Parity. Journal of Finance, L(4):1309-1319, September 1995.

[34] Mark P. Taylor, David A. Peel, and Lucio Sarno. Nonlinear mean-reversion in real exchange rates: toward a solution to the purchasing power parity puzzles. International Economic Review, 42(4):1015-1042, November 2001.

[35] Asaf Zussman. Limits to arbitrage: Trading frictions and deviations from purchasing power parity. Manuscript, December 2002. 